\title{
ATF material model development and validation for priority cladding concepts L3:FMC.FUEL.P19.07
}

K. A. Gamble, INL

August 30, 2019
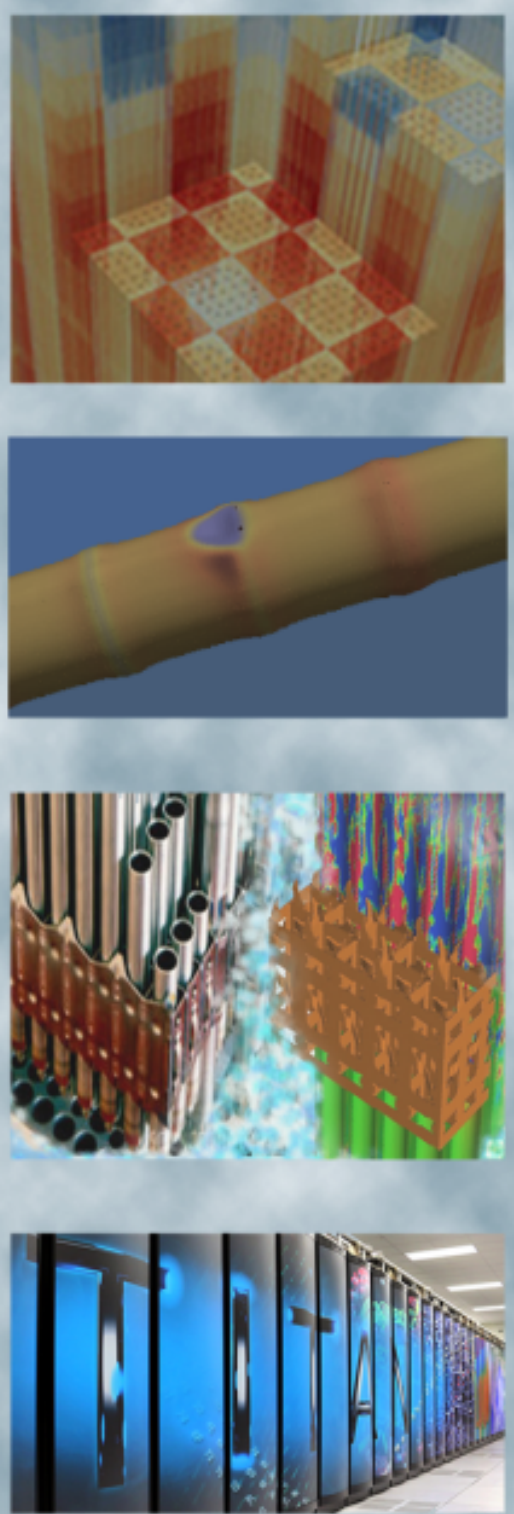
REVISION LOG

\begin{tabular}{|l|l|l|l|}
\hline Revision & Date & Affected Pages & Revision Description \\
\hline & & & \\
\hline & & & \\
\hline & & & \\
\hline & & & \\
\hline
\end{tabular}

\section{Document pages that are:}

Export Controlled NONE

IP/Proprietary/NDA Controlled NONE

Sensitive Controlled NONE

This report was prepared as an account of work sponsored by an agency of the United States Government. Neither the United States Government nor any agency thereof, nor any of their employees, makes any warranty, express or implied, or assumes any legal liability or responsibility for the accuracy, completeness, or usefulness of any information, apparatus, product, or process disclosed, or represents that its use would not infringe privately owned rights. Reference herein to any specific commercial product, process, or service by trade name, trademark, manufacturer, or otherwise, does not necessarily constitute or imply its endorsement, recommendation, or favoring by the United States Government or any agency thereof. The views and opinions of authors expressed herein do not necessarily state or reflect those of the United States Government or any agency thereof.

\section{Requested Distribution:}

To: FMC FA Lead

Copy: CASL PM 


\title{
ATF material model development and validation for priority cladding concepts
}

\author{
K. A. Gamble \\ Fuel Modeling and Simulation \\ Idaho National Laboratory \\ P.O. Box 1625 \\ Idaho Falls, ID 83415-3840
}

August 30, 2019 


\section{Contents}

1 Introduction $\quad 6$

2 Zirconium-based Clad (Zircaloy-4, M5 $^{\circledR}$, and ZIRLO ${ }^{\mathrm{TM}}$ ) 7

2.1 Thermal Properties (ThermalZry) $\ldots \ldots \ldots \ldots \ldots \ldots \ldots \ldots$

2.1.1 Model Development . . . . . . . . . . . . . . . . . . . . . . . . . . . 7

2.1 .2 Applicability and Uncertainty . . . . . . . . . . . . . . . . . . . . 8

2.2 Thermal Expansion (ZryThermalExpansionMATPROEigenstrain) . . . . . . . . . . . 9

2.2.1 Model Development . . . . . . . . . . . . . . . . . . . . . . . . . . 9

2.2 .2 Applicability and Uncertainty $\ldots \ldots \ldots \ldots \ldots$

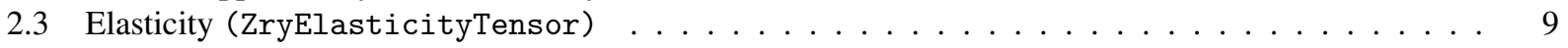

2.3.1 Model Development . . . . . . . . . . . . . . . . . . . . . . . . . 9 9

2.3.2 Applicability and Uncertainty . . . . . . . . . . . . . . . . . . . . . . . . 10

2.4 Thermal and Irradiation Creep (ZryCreepLOCAErbacherLimbackHoppeCreepUpdate) $\ldots \ldots \ldots 11$

2.4 .1 Model Development . . . . . . . . . . . . . . . . . . . . . . . . 11

2.4 .2 Applicability and Uncertainty . . . . . . . . . . . . . . . . . . . . . 11

2.5 Irradiation Growth (ZryIrradiatonGrowthEigenstrain) . . . . . . . . . . . . . . 11

2.5 .1 Model Development . . . . . . . . . . . . . . . . . . . . . . 12

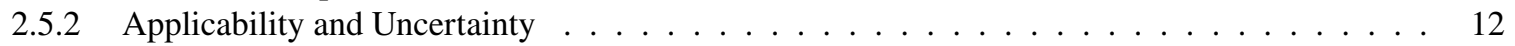

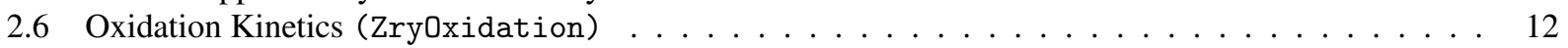

2.6 .1 Model Development . . . . . . . . . . . . . . . . . . . . . . . . . 12

2.6 .2 Applicability and Uncertainty $\ldots \ldots \ldots \ldots \ldots$

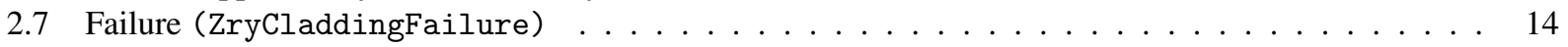

2.7 .1 Model Development . . . . . . . . . . . . . . . . . . . . . . . . . . . 14

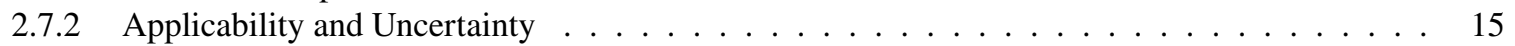

3 Chromium 16

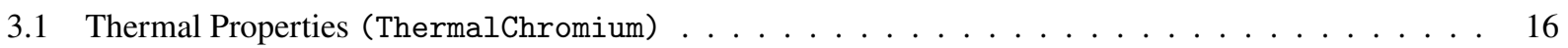

3.1.1 Model Development . . . . . . . . . . . . . . . . . . . . . . . . . . . 16

$3.1 .2 \quad$ Applicability and Uncertainty . . . . . . . . . . . . . . . . . . . 16

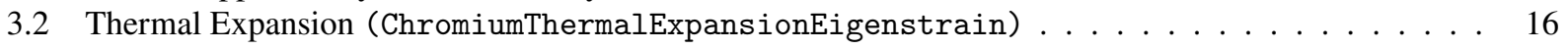

3.2.1 Model Development . . . . . . . . . . . . . . . . . . . . . . . . . . 16

$3.2 .2 \quad$ Applicability and Uncertainty . . . . . . . . . . . . . . . . . . . . . 17

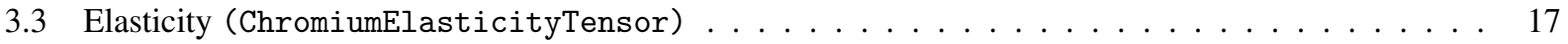

3.3 .1 Model Development . . . . . . . . . . . . . . . . . . . . . . 17

3.3 .2 Applicability and Uncertainty $\ldots \ldots \ldots \ldots \ldots \ldots \ldots \ldots \ldots$

3.4 Thermal and Irradiation Creep (ChromiumCreepUpdate) $\ldots \ldots \ldots \ldots$

3.4.1 Model Development . . . . . . . . . . . . . . . . . . . . . . . . . . . . 17

$3.4 .2 \quad$ Applicability and Uncertainty . . . . . . . . . . . . . . . . . . . . . 17

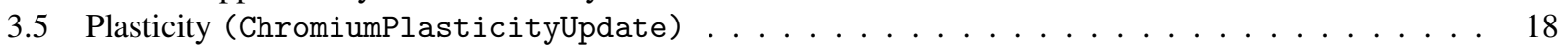

3.5.1 Model Development . . . . . . . . . . . . . . . . . . . . . . . . . 18

$3.5 .2 \quad$ Applicability and Uncertainty $\ldots \ldots \ldots \ldots \ldots \ldots$

3.6 Oxidation Kinetics (Chromiumoxidation) $\ldots \ldots \ldots \ldots \ldots \ldots \ldots$

3.6 .1 Model Development . . . . . . . . . . . . . . . . . . . . . . . . . 18

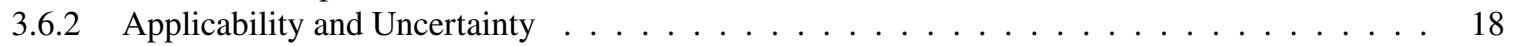

4 Iron-Chromium-Aluminum (FeCrAl) Clad 19

4.1 Thermal Properties $($ ThermalFeCrAl $) \ldots \ldots \ldots$

4.1 .1 Model Development . . . . . . . . . . . . . . . . . . . . . . . . . . . . . . 19

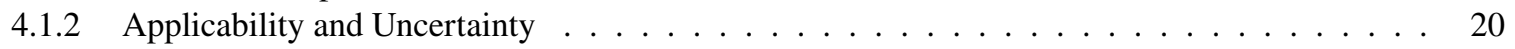

4.2 Thermal Expansion (FeCrAlThermalExpansionEigenstrain) $\ldots \ldots \ldots \ldots \ldots$

4.2 .1 Model Development . . . . . . . . . . . . . . . . . . . . . . . . 20

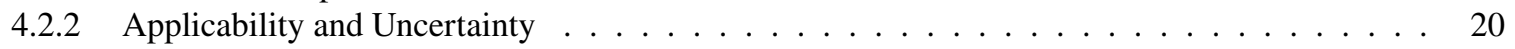

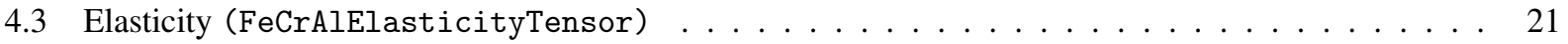




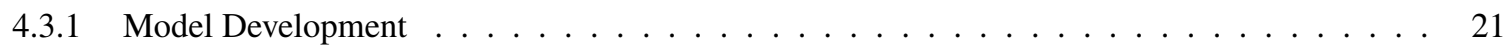

4.3.2 Applicability and Uncertainty . . . . . . . . . . . . . . . . . . . . . . 21

4.4 Thermal and Irradiation Creep (FeCrAlCreepUpdate) . . . . . . . . . . . . . . . . 23

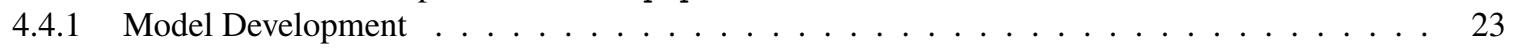

4.4 .2 Applicability and Uncertainty . . . . . . . . . . . . . . . . . . . . . . . 24

4.5 Irradiation Swelling (FeCrAlVolumetricSwellingEigenstrain) . . . . . . . . . . . 24

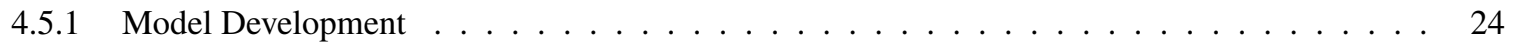

4.5.2 Applicability and Uncertainty . . . . . . . . . . . . . . . . . . . . . . . . 24

4.6 Plasticity (FeCrAlPlasticityUpdate) . . . . . . . . . . . . . . . . 25

4.6.1 Model Development . . . . . . . . . . . . . . . . . . . . . 25

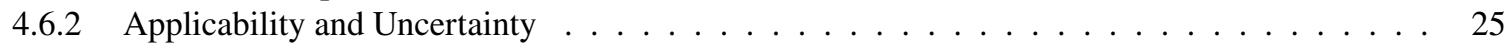

4.7 Oxidation Kinetics (FeCrAlOxidation) . . . . . . . . . . . . . . . . . . . 25

4.7.1 Applicability and Uncertainty . . . . . . . . . . . . . . . . . . . . . . . 26

4.8 Failure (FeCrAlCladdingFailure) . . . . . . . . . . . . . . . . . 26

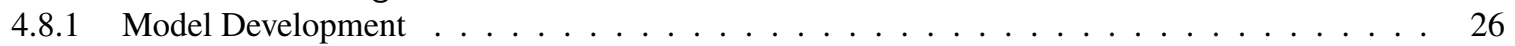

4.8.2 Applicability and Uncertainty . . . . . . . . . . . . . . . . . . . . . 26

4.9 Tritium Permeability . . . . . . . . . . . . . . . . . . . . . . . . 26

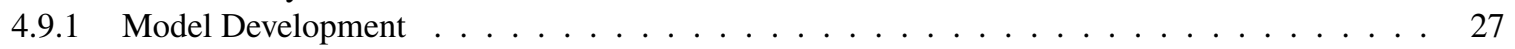

4.9 .2 Applicability and Uncertainty . . . . . . . . . . . . . . . . . . . . . . . . 28

5 Bison Demonstration Cases 29

5.1 Cr-coated Clad Ballooning Behavior . . . . . . . . . . . . . . . . . . . . . . . 29

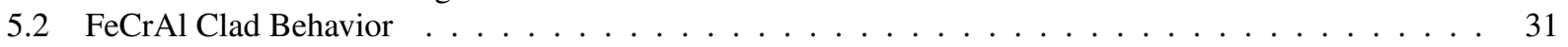

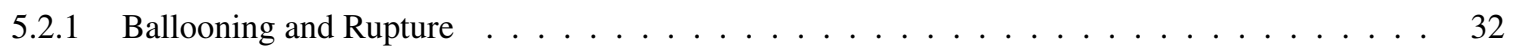

5.2 .2 Tritium Permeability . . . . . . . . . . . . . . . . . . . . . 33

6 Uncertainty Quantification and Sensitivity Analysis 35

6.1 Cr-Coated Clad Ballooning Behavior . . . . . . . . . . . . . . . . . . . . . . 35

6.2 FeCrAl Ballooning Behavior . . . . . . . . . . . . . . . . . . . . 36

7 Conclusions 39

8 Acknowledgements 40 


\section{Introduction}

Development, implementation, and validation of material and behavior models for accident tolerant fuel (ATF) concepts in the Bison fuel performance code began in 2014 in response to the events that occurred at the Fukushima Daichii nuclear power plant in March 2011. Early on the focus was on $\mathrm{U}_{3} \mathrm{Si}_{2}$ fuel and $\mathrm{FeCrAl}$ cladding as part of a high impact problem through the Nuclear Energy and Advanced Modeling Simulation (NEAMS) program. Then, developments for $\mathrm{Cr}_{2} \mathrm{O}_{3}$-doped $\mathrm{UO}_{2}$ fuel, and $\mathrm{SiC}-\mathrm{SiC}$ and $\mathrm{Cr}$-coated zirconium-based claddings began based upon industry interests. In late fiscal year 2018 the Consortium for Advanced Simulation of Light Water Reactors (CASL) took over further ATF work in Bison in support of the Nuclear Regulatory Commission (NRC) engagement. Discussions with the NRC identified their list of priority fuel and cladding concepts, which included $\mathrm{Cr}_{2} \mathrm{O}_{3}$-doped $\mathrm{UO}_{2}$ and $\mathrm{U}_{3} \mathrm{Si}_{2}$ fuels, and Cr-coated zirconium-based and FeCrAl claddings. In particular, the NRC suggested that reports similar in form to NUREG/CR-7024 [1] that was developed for traditional LWR materials $\mathrm{UO}_{2}$ and zirconium-based claddings (i.e., Zircaloy-4, M5 ${ }^{\circledR}$, ZIRLO $^{\mathrm{TM}}$ ) be created for the priority ATF concepts.

The approach to ATF capability development in Bison since the beginning has been two-fold: (1) empirical correlations and (2) multiscale model development. Both approaches have uncertainty inherent to them. Uncertainty in empirical correlations is bounded by the experimental data upon which with the correlation was developed. Models developed through a multiscale approach have uncertainty associated with the lower length scale calculations and input parameters that must be propagated to the engineering scale model in Bison. In this report, the recommended models, their range of applicability (e.g., temperature, fluence), and associated uncertainty for the NRC priority clad concepts Cr-coated zirconium based clad and $\mathrm{FeCrAl}$ are presented in a manner similar to the aforementioned NUREG. In addition, in the absence of experimental data for validation, demonstration cases are presented that investigate the ballooning and burst behavior of Cr-coated clads as well as tritium permeation in FeCrAl. A portion of the study by Gamble et al. [2] on $\mathrm{FeCrAl}$ failure is also revisited with the latest updated models. First, the nominal results are shown using the as implemented models. Then, a sensitivity analysis and uncertainty quantification is performed to assess the impact of the uncertainties in the models on the output metrics of interest. For the Cr-clad ballooning case the output of interest is the time to burst. For the revisited FeCrAl study, the output of interest is the pressure at burst. 


\section{Zirconium-based Clad (Zircaloy-4, $\mathrm{M5}^{\circledR}$, and ZIRLO ${ }^{\mathrm{TM}}$ )}

Zirconium-based clads are currently used in light water reactors as one of the barriers to radiological release. These materials can undergo rapid oxidation in high temperature steam producing volatile hydrogen that can cause an explosion. This rapid hydrogen production occurred during the Fukushima Daiichi nuclear power plant accident in 2011. A potential mitigation strategy being investigated by all fuel vendors including Global Nuclear Fuels [3], Westinghouse [4] and Framatome (formerly AREVA) [5] is to apply a thin chromium coating to the waterside surface of the clad. Chapter 3 details the models available in the Bison fuel performance code [6] for pure chromium. In this Chapter, the models available for the zirconium-based clads used by industry (Zircaloy-4, $\mathrm{M} 5^{\circledR}$, and $\mathrm{ZIRLO}{ }^{\mathrm{TM}}$ ) that will ultimately have the coating are described. The following subsections include descriptions of the models available for the zirconium-based clads including their range of applicability and associated uncertainty. All of the models in Bison for these materials are empirical in nature and therefore the uncertainty is derived from the experimental data upon which the model was created. The name of the $\mathrm{C}++$ class that computes the respective properties within Bison is listed in parentheses in the subsection header. The details described below can also be found in the online theory and user documentation packaged with the Bison code.

\subsection{Thermal Properties (ThermalZry)}

The ThermalZry material model computes the thermal conductivity and specific heat capacity for zirconium-based clads. Two different models exist for both thermal conductivity and specific heat: one taken from the MATerials PROperties (MATPRO) library [7] and a second from an International Atomic Energy Agency (IAEA) report [8].

\subsubsection{Model Development}

The specific heat correlations for the MATPRO and IAEA models are based upon experimental data for Zircaloy-2 and applied to Zircaloy-4, M5 ${ }^{\circledR}$, and ZIRLO ${ }^{\mathrm{TM}}$. Experimental data for the particular alloys of interest have not been found in the open literature. The MATPRO model for specific heat consists of a piecewise linear fit to the data provided in Table 1. Above a temperature of $1248 \mathrm{~K}$ a constant value of $356 \mathrm{~J} / \mathrm{kg}-\mathrm{K}$ is assumed.

Table 1: Temperature dependent specific heat capacity of zirconium-based alloys [7].

\begin{tabular}{cc}
\hline Temperature $(\mathrm{K})$ & Specific Heat Capacity $(\mathrm{J} / \mathrm{kg}-\mathrm{K})$ \\
\hline 300.0 & 281 \\
400.0 & 302 \\
640.0 & 331 \\
1090.0 & 375 \\
1093.0 & 502 \\
1113.0 & 590 \\
1133.0 & 615 \\
1153.0 & 719 \\
1173.0 & 816 \\
1193.0 & 770 \\
1213.0 & 619 \\
1233.0 & 469 \\
1248.0 & 356 \\
\hline
\end{tabular}

The IAEA model is a piecewise linear function designed to account for the $\alpha$ to $\beta$ phase transition that occurs in 
zirconium-based alloys. Therefore, a different equation applies depending upon the temperature range.

$$
C_{p}= \begin{cases}255.66+0.1024 T & \text { for } 273 \mathrm{~K}<T<1100 \mathrm{~K} \\ 255.66+0.1024 T+1058.4 \exp \left(\frac{-(T-1213.8)^{2}}{719.61}\right) & \text { for } 1100 \mathrm{~K}<T<1214 \mathrm{~K} \\ 597.1-0.4088 T+1.565 \times 10^{-4} T^{2}+1058.4 \exp \left(\frac{-(T-1213.8)^{2}}{719.61}\right) & \text { for } 1214 \mathrm{~K}<T<1320 \mathrm{~K} \\ 597.1-0.4088 T+1.565 \times 10^{-4} T^{2} & \text { for } 1320 \mathrm{~K}<T<2000 \mathrm{~K}\end{cases}
$$

where $T$ is the temperature in $\mathrm{K}$, and the calculated specific heat capacity $C_{p}$ has units of $\mathrm{J} / \mathrm{kg}-\mathrm{K}$. For the development of the MATPRO and IAEA thermal conductivity models, experimental data for Zircaloy-2 and Zircaloy-4 were used. In absence of other data these correlations are also applied to M $5^{\circledR}$ and $Z$ IRLO $^{\mathrm{TM}}$. The MATPRO model for thermal conductivity [7] is given by:

$k=7.511+2.088 \times 10^{-2} T-1.450 \times 10^{-5} T^{2}+7.668 \times 10^{-9} T^{3}$

where $T$ the temperature in $\mathrm{K}$ and $k$ is the thermal conductivity in W/m-K. The IAEA model for thermal conductivity [8] is given by:

$k=12.767-5.4348 \times 10^{-4} T+8.9818 \times 10^{-6} T^{2}$

where $T$ is the temperature in $\mathrm{K}$ and $k$ is the thermal conductivity in $\mathrm{W} / \mathrm{m}-\mathrm{K}$.

\subsubsection{Applicability and Uncertainty}

The MATPRO specific heat and thermal conductivity models are applicable $298 \mathrm{~K}$ to $2098 \mathrm{~K}$. The IAEA specific heat and thermal conductivity models are valid from $273 \mathrm{~K}$ to $2000 \mathrm{~K}$ and $300 \mathrm{~K}$ to $1800 \mathrm{~K}$, respectively.

The uncertainty of the MATPRO models have been reported by [9]. For the specific heat the uncertainty is dependent upon the temperature range as reported in Table 2 . The uncertainty in the thermal conductivity model is reported as \pm $2.02 \%$. Uncertainties correspond to a 95\% confidence assuming a Gaussian distribution.

Table 2: Uncertainty in the MATPRO specific heat model as a function of temperature.

\begin{tabular}{ll}
\hline Temperature Range & Uncertainty $(\mathrm{J} / \mathrm{kg}-\mathrm{K})$ \\
\hline $298 \leq \mathrm{T} \leq 800 \mathrm{~K}$ & \pm 1.1 \\
$800 \mathrm{~K}<\mathrm{T} \leq 1090 \mathrm{~K}$ & \pm 2.8 \\
$1090 \mathrm{~K}<\mathrm{T} \leq 1248 \mathrm{~K}$ & \pm 10.7 \\
$1248 \mathrm{~K}<\mathrm{T} \leq 2098 \mathrm{~K}$ & \pm 100.0 \\
\hline
\end{tabular}

According to the IAEA report [8], the uncertainty in the IAEA specific heat model varies as a function of temperature. Table 3 provides the reported uncertainty. For thermal conductivity the authors of the IAEA report provide a temperature varying uncertainty of one standard deviation. In this work an uncertainty of two standard deviations is reported and tabulated in Table 4.

Table 3: Uncertainty in the IAEA specific heat model as a function of temperature.

\begin{tabular}{ll}
\hline Temperature Range & Uncertainty $(\%)$ \\
\hline $298 \leq \mathrm{T} \leq 1100 \mathrm{~K}$ & \pm 3 \\
$1100 \mathrm{~K}<\mathrm{T} \leq 1300 \mathrm{~K}$ & \pm 10 \\
$1300 \mathrm{~K}<\mathrm{T} \leq 1600 \mathrm{~K}$ & \pm 10 \\
$1600 \mathrm{~K}<\mathrm{T} \leq 1700 \mathrm{~K}$ & Linear Interpolation between \pm 10 and \pm 20 \\
$\mathrm{~T}>1700 \mathrm{~K}$ & \pm 20 \\
\hline
\end{tabular}


Table 4: Uncertainty in the IAEA thermal conductivity model as a function of temperature.

\begin{tabular}{ll}
\hline Temperature Range & Uncertainty (\%) \\
\hline $300 \mathrm{~K}$ & \pm 8 \\
$300 \mathrm{~K}<\mathrm{T} \leq 500 \mathrm{~K}$ & Linear Interpolation between 8 and 10 \\
$500 \mathrm{~K}<\mathrm{T} \leq 800 \mathrm{~K}$ & Linear Interpolation between 10 and 12 \\
$800 \mathrm{~K}<\mathrm{T} \leq 1200 \mathrm{~K}$ & Linear Interpolation between 12 and 14 \\
$1200 \mathrm{~K}<\mathrm{T} \leq 1800 \mathrm{~K}$ & \pm 14 \\
\hline
\end{tabular}

\subsection{Thermal Expansion (ZryThermalExpansionMATPROEigenstrain)}

The ZryThermalExpansionMATPROEigenstrain model computes the anisotropic thermal strains of zirconiumbased clads.

\subsubsection{Model Development}

The model used is from Version 11 of the MATPRO library [10] and is based upon Zircaloy-2 and Zircaloy-4 data and is applied to M5 ${ }^{\circledR}$ and ZIRLO ${ }^{\mathrm{TM}}$ in absence of publicly available data. In the $\alpha$-phase (T $<1073 \mathrm{~K}$ ):

$\epsilon_{\text {axial }}=-2.5060 \times 10^{-5}+4.441 \times 10^{-6} T_{c}$

$\epsilon_{\text {dia }}=-2.373 \times 10^{-4}+6.721 \times 10^{-6} T_{c}$

where $\epsilon_{\text {axial }}$ is the axial thermal strain, $\epsilon_{d i a}$ is the diametrical thermal strain, and $T_{c}$ is the temperature in ${ }^{\circ} \mathrm{C}$. In the $\beta$-phase ( $\mathrm{T}>1244 \mathrm{~K})$ :

$\epsilon_{\text {axial }}=-8.3 \times 10^{-3}+9.7 \times 10^{-6} T_{c}$

$\epsilon_{\text {dia }}=6.8 \times 10^{-3}+9.7 \times 10^{-6} T_{c}$

where linear interpolation between the $\alpha$ and $\beta$-phase values is used in the $(\alpha+\beta)$-phase $(1073 \mathrm{~K} \leq \mathrm{T} \leq 1244 \mathrm{~K})$.

\subsubsection{Applicability and Uncertainty}

The range of applicability of the Version 11 MATPRO model for thermal expansion of zirconium-based alloys in this work is from $298 \mathrm{~K}$ to $2098 \mathrm{~K}$. The uncertainty is reported in [10] to vary depending upon the phase. In the $\alpha$-phase $(T<1073 \mathrm{~K})$ the uncertainty is $\pm 10 \%$. In the transition region and in the $\beta$ phase the data is much more limited and therefore an uncertainty of $\pm 50 \%$ is assumed.

\subsection{Elasticity (ZryElasticityTensor)}

The ZryElasticityTensor model computes the elasticity tensor of zirconium-based clads using the model from the MATPRO library [7].

\subsubsection{Model Development}

The Young's modulus in the $\alpha$-phase is calculated by:

$E=\frac{1.088 \times 10^{11}-5.475 \times 10^{7}+K_{1}+K_{2}}{K_{3}}$ 
where $T$ is the temperature in $\mathrm{K}$, and $K_{1}, K_{2}$, and $K_{3}$ are scaling factors that depend upon oxidation, cold work, and fast neutron fluence, respectively. In the $\beta$-phase the Young's modulus is given by:

$E=9.21 \times 10^{10}-4.05 \times 10^{7} T$

where the scaling factors are given by:

$K_{1}=\left(6.61 \times 10^{11}+5.912 \times 10^{8} T\right) \Delta$

$K_{2}=-2.6 \times 10^{10} C$

$K_{3}=0.88+0.12 \exp \left(-\frac{\Phi}{10^{25}}\right)$

where $\Delta$ is average oxygen concentration minus the oxygen concentration of the as-received alloy, $C$ is the cold work ratio, and $\Phi$ is the fast neutron fluence in $\mathrm{n} / \mathrm{m}^{2}$. The shear modulus in the $\alpha$-phase is given by:

$G=\frac{4.04 \times 10^{10}-2.168 \times 10^{7} T+K_{1}+K_{2}}{K_{3}}$

In the $\beta$-phase:

$G=3.49 \times 10^{10}-1.66 \times 10^{7} T$

where the scale factors $K_{2}$ and $K_{3}$ are the same as for Young's modulus and $K_{1}$ becomes:

$K_{1}=\left(7.07 \times 10^{11}-2.315 \times 10^{8} T\right) \Delta$

Then, given $E$ and $G$ one can calculate the Poisson's ratio through:

$\nu=\frac{E}{2 G}-1$

For the cold work ratio $C$ in the equation for $K_{2}$, varies depending upon the alloy of interest. The authors of NUREG/CR7024 [9] report nominal values for Zircaloy-4, ZIRLO ${ }^{\mathrm{TM}}$, and M5 ${ }^{\circledR}$ as provided in Table 5.

Table 5: The nominal cold work for the various zirconium-baased clads.

\begin{tabular}{lc}
\hline Zircaloy Material Type & Cold Work (\%) \\
\hline Zircaloy-4 & 50 \\
ZIRLO $^{\mathrm{TM}}$ & 50 \\
$\mathrm{M} 5^{\circledR}$ & 0 \\
\hline
\end{tabular}

\subsubsection{Applicability and Uncertainty}

The Young's and Shear moduli correlations are applicable from $298 \mathrm{~K}$ to $2098 \mathrm{~K}$. The uncertainty associated with these calculations have been reported by [9] as 6.4 GPa and 9.0 GPa for the Young's modulus and Shear modulus, respectively. Using the general error propagation formula one can derive the uncertainty of the Poisson's ratio:

$$
\begin{aligned}
& \delta \nu=\sqrt{\left(\frac{\partial \nu}{\partial E} \delta E\right)^{2}+\left(\frac{\partial \nu}{\partial G} \delta G\right)^{2}} \\
& \delta \nu=\sqrt{\left(\frac{1}{2 G}\left(6.4 \times 10^{9}\right)\right)^{2}+\left(\frac{E}{2 G^{2}}\left(9.0 \times 10^{9}\right)\right)^{2}}
\end{aligned}
$$




\subsection{Thermal and Irradiation Creep (ZryCreepLOCAErbacherLimbackHoppeCreepUpdate)}

The ZryCreepLOCAErbacherLimbackHoppeCreepUpdate model computes the creep behavior of zirconium-based clads under both normal operating and accident conditions. The low temperature model computes different creep rates depending upon the microstructure or material type (i.e., Zircaloy- $4, \mathrm{M}^{\circledR}, \mathrm{ZIRLO}^{\mathrm{TM}}$ ), whereas the high temperature correlation was developed on Zircaloy-4 specimens but is applied to all types of zirconium-based clad.

\subsubsection{Model Development}

Under accident conditions $(T \geq 900 \mathrm{~K})$, such as experienced during a LOCA the creep rate is modeled through a Norton model [11]:

$\dot{\epsilon}=A \sigma_{\text {eff }}^{n} \exp \left(\frac{-Q}{R T}\right)$

where $A$ is the creep coefficient, $n$ is the stress exponent, and $Q$ is the activation energy. These parameters depend upon the phase of the alloy as summarized in Table 6.

Table 6: Parameters for high temperature creep as a function of phase

\begin{tabular}{lccc}
\hline Phase & $\mathrm{A}\left(\mathrm{MPa}^{-n} \mathrm{~s}^{-1}\right)$ & $\mathrm{Q}(\mathrm{kJ} / \mathrm{mol})$ & $\mathrm{n}$ \\
\hline$\alpha$ & 8737 & See Equation 20 & 5.89 \\
$50 \% \alpha-50 \% \beta$ & 0.24 & $1.02366 \times 10^{5}$ & 2.33 \\
$\beta$ & 7.9 & $1.41919 \times 10^{5}$ & 3.78 \\
\hline
\end{tabular}

where

$Q=3.21 \times 10^{5}+24.69(T-923.15)$

Linear interpolation is used for mixed phases not equal to $50 \% \alpha-50 \% \beta$ for strain rates less than $3 \times 10^{-3} \mathrm{~s}^{-1}$. For creep rates above this value linear interpolation is used for $Q$ and $n$ and linear interpolation of $\ln (A)$ are used for $A$. For low temperature creep, the Limbäck and Andersson [12] correlations are used for primary, secondary, and irradiation creep. In the intermediate temperature regime, linear interpolation is used between the two thermal creep correlations.

\subsubsection{Applicability and Uncertainty}

The low temperature correlations of Limbäck and Andersson is only applicable up $700 \mathrm{~K}$, effective stress ranges of 40 to $130 \mathrm{MPa}$, and fast neutron fluxes from $1 \times 10^{17}$ to $2.0 \times 10^{18} \mathrm{n} / \mathrm{m}^{2}$-s as per [9]. The high temperature model proposed by [11] is valid for temperatures from $900 \mathrm{~K}$ to $\sim 1600 \mathrm{~K}$. As mentioned previously, in the intermediate region linear interpolation is used between the two models. Depending upon the microstructure of the clad used in the low temperature correlation the uncertainty has been reported to vary between $\pm 14.5 \%$ to $21.6 \%$ by [9]. The high temperature model is independent of clad type. Given the larger uncertainty in measurements at high temperatures and calculation of the phase of the alloy an uncertainty of $\pm 30 \%$ is suggested for the high temperature creep model.

\subsection{Irradiation Growth (ZryIrradiatonGrowthEigenstrain)}

The ZryIrradiationGrowthEigenstrain model in Bison accounts for the dimensional changes in the axial and diametrical directions due to the phenomenon of irradiation growth. 


\subsubsection{Model Development}

The model for irradiation growth of zirconium alloy cladding calculates the increment of cladding axial strain due to irradiation growth, and was obtained from [13].

$\epsilon_{\text {irr }}=A \Phi^{n}$

where $A$ is a coefficient determined by the zircaloy material type in units of $\left(\mathrm{cm}^{2} / \text { neutrons }\right)^{n}$, $\Phi$ is the total fast neutron fluence in neutrons $/ \mathrm{cm}^{2}$, and $n$ is the fluence exponent (dimensionless). Additional sets of material properties, using the same irradiation growth strain relationship, are from [9] and [14].

Table 7: Material Parameters for irradiation growth strain for various Zircaloy microstructures [9, 13, 14].

\begin{tabular}{lcc}
\hline Zircaloy Material Type & Irradiation Growth Strain Coefficient (A) & Irradiation Growth Exponent (n) \\
\hline Zircaloy-4 (Franklin model) & $2.18 \times 10^{-21}$ & 0.845 \\
ZIRLO $^{\text {TM }}$ (Irisa model $)$ & $9.7893 \times 10^{-25}$ & 0.98239 \\
$\mathrm{M5}^{\circledR}($ Gilbon model $)$ & $7.013 \times 10^{-21}$ & 0.81787 \\
\hline
\end{tabular}

This method builds the irradiation growth strain tensor based on the geometry options set by the user. Since irradiation growth should occur in the axial direction only while being volume conserving, it is necessary to specify a strain increment for the other two directions. This strain increment is given by

$\Delta \epsilon_{\text {lateral }}=-\left(1.0-\left(1.0+\Delta \epsilon_{\text {axial }}\right)^{-0.5}\right)$

\subsubsection{Applicability and Uncertainty}

The irradiation growth model is reported to be applicable up to fast neutron fluences of $\Phi<12 \times 10^{26}$ in [9]. The uncertainty in the calculated irradiation strain depends upon the alloy as shown in Table 8.

Table 8: Uncertainty in the MATPRO specific heat model as a function of temperature.

\begin{tabular}{ll}
\hline Zircaloy Material Type & Uncertainty $(\%)$ \\
\hline Zircaloy-4 & \pm 22.3 \\
ZIRLO $^{\mathrm{TM}}$ & \pm 18.6 \\
M5 $^{\circledR}$ & \pm 44.8 \\
\hline
\end{tabular}

\subsection{Oxidation Kinetics (ZryOxidation)}

Bare zirconium-based undergo oxidation during normal operation and accident conditions (e.g., Loss of Coolant Accident (LOCA)). The kinetics of Zircaloy-4 is well studied and Bison contains many different models to capture the kinetics. Here, default low temperature and high temperature correlation used in Bison are presented. Bison does not contain specific oxidation models $\mathrm{M}^{\circledR}$ and $\mathrm{ZIRLO}^{\mathrm{TM}}$ because no data is publicly available. It is expected that these two zirconium-based alloys will experience significantly less oxide growth during normal operation and accidents than Zircaloy-4.

\subsubsection{Model Development}

In the low temperature (normal operating) regime ( $523 \mathrm{~K}$ to $673 \mathrm{~K}$ ) oxidation of Zircaloy occurs in two stages: a pretransition oxidation process that follows a cubic time dependence up to a transition oxide thickness, and a post-transition process that follows a linear time dependence. The transition between the two stages occurs at 2 microns. 
For the pre-transition period, the corrosion rate is given by an Arrhenius equation [15]:

$\frac{d S^{3}}{d t}=C_{1} \exp \left(\frac{-Q_{1}}{R T_{I}}\right)$, for $S \leq S_{\text {trans }}$.

For the post-transition period, the corrosion rate is given by [15]:

$\frac{d S}{d t}=C_{2} \exp \left(\frac{-Q_{2}}{R T_{I}}\right)$, for $S>S_{\text {trans }}$

where $S$ is the oxide thickness, $T_{I}$ is the metal-oxide interface temperature, $C_{1}$ is the rate constant for pre-transition oxidation, $Q_{1}$ is the activation energy for pre-transition oxidation, $C_{2}$ is the rate constant for post-transition oxidation, $Q_{2}$ is the activation energy for post-transition oxidation, $R$ is the universal gas constant, and $S_{\text {trans }}$ is the transition oxide thickness.

In Bison below $673 \mathrm{~K}$ the EPRI/KWU/C-E oxidation model $[16,17]$ is used. The values for the expressions given in Equations 23 and 24 are provided in Table 9.

Table 9: Parameters used in the EPRI/KWU/C-E oxidation model [16, 17].

\begin{tabular}{cc}
\hline Model Expression & Parameter Value \\
\hline$C_{1}$ & $6.3 \times 10^{9} \mu \mathrm{m}^{3} /$ day \\
$\frac{Q_{1}}{R}$ & $16266 \mathrm{~K}$ \\
$C_{2}$ & $0.0410^{7}+2.5910^{8}\left(7.4610^{-15} \phi\right)^{0.25} \mu \mathrm{m}^{3} /$ day \\
$\frac{Q_{2}}{R}$ & $13775 \mathrm{~K}$ \\
\hline
\end{tabular}

where $\phi$ is the fast neutron flux in $\mathrm{n} / \mathrm{cm}^{2}$-s. $C_{2}$ accounts for the irradiation enhancement to corrosion.

In the high temperature range $(T>673 \mathrm{~K})$ such as occurs during accident conditions the coolant has become steam, and oxidation proceeds much more rapidly. Under these conditions, the kinetics of oxide scale growth and oxygen mass gain in the cladding can be described by a parabolic law, with the reaction rate constant defined as a function of the temperature through an Arrhenius relation [18]

$\frac{d \xi^{2}}{d t}=A \exp \left(\frac{-Q}{R T_{I}}\right)$

where $\xi$ is either the oxide scale thickness, $\xi=\mathrm{S}(\mathrm{m})$, or the oxygen mass, $\xi=\mathrm{g}\left(\mathrm{kgm}^{-2}\right), T_{I}$ is the metal-oxide interface temperature $(\mathrm{K}), A$ is the oxidation rate constant $\left(\mathrm{m} \mathrm{or} \mathrm{kgm}{ }^{-2}\right), Q$ is the activation energy $(\mathrm{J} / \mathrm{mol})$, and $R$ is the universal gas constant $(\mathrm{J} / \mathrm{mol}-\mathrm{K})$.

Following the recommendations [18], the Bison model includes correlations for oxide scale growth and oxygen mass gain rates in Zircaloy-2/4 appropriate to different temperature ranges. In particular, the following approach is adopted:

For metal-oxide interface temperatures from $673 \mathrm{~K}$ up to $1800 \mathrm{~K}$, the Leistikov [19] correlation is used. The CathcartPawel correlation [20] is also available and can be chosen as an option. The Leistikov correlation has been selected as reference in view of the larger underlying database, the availability of experimentally determined mass gain for all tests, and the better fit for lower temperature when compared to the Cathcart-Pawel correlation [18]. Above 1900 K, the Prater-Courtright correlation [21] is used. Between 1800 and $1900 \mathrm{~K}$, a linear interpolation is made. Linear interpolation between two correlations of Arrhenius type is obtained by a third correlation of the same type [18].

The values of the parameters in Equation 25 relative to the different correlations are given in 10.

\subsubsection{Applicability and Uncertainty}

The oxidation model for zirconium-based clads in Bison has rate laws applicable through all temperature ranges that can be experienced in a reactor including normal operating and accident conditions. The uncertainty in cladding corrosion has been reported by [22] to be $\pm 40 \%$. 
Table 10: Parameters of the correlations for oxide scale (S) and oxygen mass gain $(\mathrm{g})$ at high temperature [18].

\begin{tabular}{lcccc}
\hline Correlation & $A_{S}\left(\mathrm{~m}^{2} \mathrm{~s}^{-1}\right)$ & $\frac{Q_{S}}{R}(\mathrm{~K})$ & $A_{g}\left(\mathrm{kgm}^{-2}\right)$ & $\frac{Q_{g}}{R}(\mathrm{~K})$ \\
\hline Leistikov & $7.82 \times 10^{-6}$ & 20214 & 52.42 & 20962 \\
Cathcart-Pawel & $2.25 \times 10^{-6}$ & 18062 & 36.22 & 20100 \\
Prater-Courtright & $2.98 \times 10^{-3}$ & 28420 & $3.3 \times 10^{3}$ & 26440 \\
\hline
\end{tabular}

\subsection{Failure (ZryCladdingFailure)}

The time of burst (failure) of zirconium-based cladding tubes during LOCA conditions is determined from the ZryCladdingFailure model. Although the model was originally developed for Zircaloy-4, in the absence of publicly available data to the contrary, the model is applied to M5 ${ }^{\circledR}$ and ZIRLO ${ }^{\mathrm{TM}}$. Four different options (OVERSTRESS, PLASTIC_INSTABILITY, COMBINED, OVERSTRAIN) are available depending upon the outputs of interest (e.g., time to burst, final clad diameter profile).

\subsubsection{Model Development}

The OVERSTRESS criterion assumes that the time of burst of the clad occurs when the local hoop is equal to or greater than a limiting burst stress [11]:

$\sigma_{\theta} \geq \sigma_{b}$

where $\sigma_{\theta}$ is the hoop stress in MPa and $\sigma_{b}$ is the burst stress in MPa. Based on experimental evidence, the burst stress is considered to depend on the temperature and oxygen concentration in the cladding and is represented by:

$\sigma_{b}=a \exp (-b T) \exp \left[-\left(\frac{\eta-\eta_{0}}{9.510^{-4}}\right)^{2}\right]$

where $a(\mathrm{MPa})$ and $b\left(\mathrm{~K}^{-1}\right)$ are constants determined experimentally, and $\eta$ (dimensionless) is the oxygen weight fraction in the cladding. An oxygen weight fraction at fabrication, $\eta_{0}=1.2 \times 10^{-3}$, is used following [11]. The current oxygen weight fraction is computed based on the oxygen mass gain from the oxidation model as

$\eta=\frac{2 r_{c l, o}}{\rho_{Z y}\left(r_{m e t, o}^{2}-r_{c l, i}^{2}\right)} g+\eta_{0}$

where $r_{c l, o}$ is the cladding outer radius in $\mathrm{m}, \rho_{Z y}=6550 \mathrm{~kg} / \mathrm{m}^{3}$ is the density of the cladding metal, $r_{c l, i}$ is the cladding inner radius in, $\mathrm{g}$ is the oxygen mass in $\mathrm{kg} / \mathrm{m}^{2}$ calculated from the oxidation model described in Section 2.6 , and $r_{m e t, o}=r_{c l, o}-S / R_{P B}$ where $\mathrm{S}$ is the oxide layer thickness in $\mathrm{m}$, and $\mathrm{R}_{P B}=1.56$ is the Pilling-Bedworth ratio for Zircaloy.

The values for the parameters a and $\mathrm{b}$ are given in the table for material parameters depending on phase. In the mixed phase $(\alpha+\beta)$ region, linear interpolations of $\ln (a)$ and $b$ are made between the values for pure $\alpha$ and the middle of the $\alpha+\beta(50 \% \alpha 50 \% \beta)$ phase, and between $50 \% \alpha 50 \% \beta$ and pure $\beta$ phase, [11].

Table 11: Material parameters used to calculate the burst stress of Zircaloy-4 [11]

\begin{tabular}{ccc}
\hline Zr Phase & $\mathrm{a}(\mathrm{MPa})$ & $\mathrm{b}\left(\mathrm{K}^{-1}\right)$ \\
\hline$\alpha$ & 830 & $1.0 \times 10^{-3}$ \\
$50 \% \alpha 50 \% \beta$ & 3000 & $3.0 \times 10^{-3}$ \\
$\beta$ & 2300 & $3.0 \times 10^{-3}$ \\
\hline
\end{tabular}

The PLASTIC_INSTABILITY criterion considers cladding failure when the effective plastic strain rate reaches a limiting value:

$\dot{\epsilon}_{p l, e f f} \geq \dot{\epsilon}_{b}$ 
where $\dot{\epsilon}_{p l, e f f}$ is the effective plastic (creep + plasticity) strain rate and $\dot{\epsilon}_{b}$ is the limiting value. Following [23], $\dot{\epsilon}_{b}=100$ $\mathrm{h}^{-1} \cong 2.7810^{-2} \mathrm{~s}^{-1}$.

It is cautioned that the OVERSTRESS criterion not be used on its own because under low stress loading conditions the prediction of the burst stress may lead to an incorrect computation of the burst time [23]. Thus, a COMBINED failure criterion, which determines burst when either condition given by Equation 26 or Equation 29 is fulfilled is suggested.

The final option available is the OVERSTRAIN criterion which determines cladding failure once the true inelastic hoop strain exceeds a value of $33.6 \%$ :

$\epsilon_{\theta, \text { creep }} \geq 0.336$

\subsubsection{Applicability and Uncertainty}

The OVERSTRESS criterion is only applicable for use on clad specimens that have not been pre-oxidized as the burst stress correlation was originally developed on fresh clad specimens subjected to high temperature steam oxidization. Application to clad tubes that have been pre-irradiated (and oxidized) prior to the LOCA tests leads to premature predictions of failure during the normal operation base irradiation. As mentioned previously the OVERSTRESS criterion does not predict the time to failure accurately for low stress conditions. The PLASTIC_INSTABILITY model is applicable for all conditions until the strain rate reaches the critical limit. The use of the COMBINED model eliminates the issue of low stress conditions associated with the OVERSTRESS criterion. However, the COMBINED model should not be applied on pre-irradiated rods that oxidize as failure will still be predicted early. The OVERSTRAIN criterion is applicable under all normal operating and accident conditions until the inelastic strain limit is attained. The limiting values chosen for all of the models is based upon comparisons to a wide variety of experiments. Uncertainty exists in these values but have not been reported in the literature. 


\section{Chromium}

Chromium is the material that is being considered as a coating on the waterside surface of zirconium-based clads to mitigate excessive oxidation and hydrogen production that can occurring Loss of Coolant Accidents. The following subsections include descriptions of the models available in Bison for pure chromium including their range of applicability and associated uncertainty. All of the models in Bison for these materials are empirical in nature and therefore the uncertainty is derived from the experimental data upon which the model was created and from the understanding of similar materials. The name of the $\mathrm{C}++$ class that computes the respective properties within Bison is listed in parentheses in the subsection header. The details described below can also be found in the online theory and user documentation packaged with the Bison code. All of the models for chromium available in Bison have been compiled by [24] based upon the work of [25-27].

\subsection{Thermal Properties (ThermalChromium)}

The ThermalChromium model computes the thermal properties of chromium metal including the thermal conductivity and specific heat capacity.

\subsubsection{Model Development}

The thermal conductivity of chromium is given by:

$k=-2.07 \times 10^{-7} T^{3}+4.85 \times 10^{-5} T^{2}-0.06 T+101.75$

where $T$ is the temperature in $\mathrm{K}$, and $k$ is the thermal conductivity in $\mathrm{W} / \mathrm{m}-\mathrm{K}$. The specific heat is given by:

$C_{p}=-1.28 \times 10^{-7} T^{3}+3.39 \times 10^{-4} T^{2}-0.09 T+483.2$

where $T$ is the temperature in $\mathrm{K}$, and $C_{p}$ is the specific heat in $\mathrm{J} / \mathrm{kg}-\mathrm{K}$.

\subsubsection{Applicability and Uncertainty}

Both the thermal conductivity and specific heat models are applicable over the temperature range of $300 \mathrm{~K}$ to 1300 $\mathrm{K}$. Since chromium is being used as a coating, the thickness is small relative to the total clad thickness and since the thermal conductivity from the nominal equation is large, the temperature drop across the coating will be minimal. Thus, changes in the thermal conductivity will not greatly affect the results and therefore a small uncertainty of $\pm 5 \%$ is suggested. For the specific heat an uncertainty of $\pm 10 \%$ is suggested.

\subsection{Thermal Expansion (ChromiumThermalExpansionEigenstrain)}

The ChromiumThermalExpansionEigenstrain material class calculates the thermal strains associated with expansion.

\subsubsection{Model Development}

The mean linear thermal expansion coefficient a function of temperature:

$\bar{\alpha}=\left(1.27 \times 10^{-10} T^{3}+5.41 \times 10^{-7} T^{2}+0.0015 T+7.87\right) \times 10^{-6}$

where $T$ is the temperature in $\mathrm{K}$, and $\bar{\alpha}$ is the mean thermal expansion in $\mathrm{K}^{-1}$. The method of [28] is employed to convert the mean thermal expansion values into instantaneous values using a reference temperature of $293 \mathrm{~K}$. 


\subsubsection{Applicability and Uncertainty}

The computation of the mean linear thermal expansion coefficient is valid over a temperature range of $300 \mathrm{~K}$ to 1300 $\mathrm{K}$. The correlation may not be applicable to chromium produced from different manufacturers. Thus, to capture the possible variability an uncertainty of $\pm 10 \%$ is suggested.

\subsection{Elasticity (ChromiumElasticityTensor)}

The ChromiumElasticityTensor model computes the elasticity tensor of chromium from the Poisson's ratio and Young's modulus.

\subsubsection{Model Development}

The Poisson's ratio for pure chromium is constant and assumed to be equal to 0.22 . The Young's modulus is a temperature dependent function given by:

$E=-2.50 \times 10^{-5} T^{2}-0.01 T+264.11$

where $E$ is the Young's modulus in GPa, and $T$ is the temperature in K.

\subsubsection{Applicability and Uncertainty}

The constant value for the Poisson's ratio and the correlation for Young's modulus is valid over a temperature range of $300 \mathrm{~K}$ to $1500 \mathrm{~K}$. The fit provided by 34 has a limited uncertainty with the data it was developed upon. However, the correlation may not be directly applicable to chromium produced from different manufacturers. Therefore, to capture variability in the manufacturing of chromium uncertainties on the Young's modulus and Poisson's ratios are taken as $\pm 10 \%$ and $\pm 15 \%$ respectively, which is similar to other metallic materials.

\subsection{Thermal and Irradiation Creep (ChromiumCreepUpdate)}

The ChromiumCreepUpdate model computes the secondary creep of chromium. Data on irradiation creep is not publicly available and Bison does not have a model for the irradiation creep of chromium.

\subsubsection{Model Development}

The thermal creep correlation is in the form of a Norton creep law:

$\dot{\epsilon}=3.2555 \times 10^{-40} \sigma^{6.2} \exp \left(\frac{306268.8}{R T}\right)$

where $R$ is the ideal gas constant with a value of $8.3145 \mathrm{~J} / \mathrm{mol}-\mathrm{K}$ and $T$ is the temperature in $\mathrm{K}$.

\subsubsection{Applicability and Uncertainty}

According to [29] the temperature range of applicability for the thermal creep correlation is given as a homologous temperature range reported as a percentage of the melting temperature. This range is given as $0.51 \mathrm{~T}_{m} \leq \mathrm{T} \leq 0.78 \mathrm{~T}_{m}$. Limited data was used to develop the creep correlation for chromium. Consequently, the uncertainty in the predictions would be large. A value of $\pm 20 \%$ is chosen in Bison. 


\subsection{Plasticity (ChromiumPlasticityUpdate)}

The ChromiumPlasticityUpdate model calculates the plastic strain for chromium cladding materials as a function of temperature including the effect of irradiation hardening.

\subsubsection{Model Development}

The yield stress as a function of temperature is given by [24]:

$\sigma_{y}=-8.24 \times 10^{-7} T^{3}+0.0019 T^{2}-1.39 T+513.17$

where $\sigma_{y}$ is the yield stress in MPa and $T$ is the temperature in K. Irradiation hardening is then included via:

$\sigma_{y_{i r r}}=\sigma_{y}\left(5.0 \times 10^{-27} \Phi+1\right)$

where $\Phi$ is the fast neutron fluence in $\mathrm{n} / \mathrm{m}^{2}$.

\subsubsection{Applicability and Uncertainty}

The temperature dependence of the yield stress is valid from $300 \mathrm{~K}$ to $1500 \mathrm{~K}$ and the irradiation hardening correlation is valid for fluences less than $10^{26} \mathrm{n} / \mathrm{m}^{2}$. Given the current application of using chromium as a coating it will likely immediately undergo plastic deformation. Accordingly, the uncertainty is assumed to be $\pm 15 \%$ due to the limited amount of available experimental data.

\subsection{Oxidation Kinetics (ChromiumOxidation)}

\subsubsection{Model Development}

The material ChromiumOxidation models oxidation and corrosion of chromium. According to [24] the oxide mass gain is given by a parabolic rate law that is 15 times less than the model of [19] for zirconium based alloys. Therefore, the oxide weight gain is given by:

$w_{g}=4.83 \times 10^{-3} \exp \left(-\frac{10481}{T}\right) t^{1 / 2}$

where $w_{g}$ is the mass gain in $\mathrm{g} / \mathrm{cm}^{2}$ and $t$ is the time in seconds. A conversion factor of $2.22 \times 10^{3} \mu \mathrm{m}-\mathrm{cm}^{2} / \mathrm{g}$ is used to convert the calculated weight gain to oxide thickness in $\mu \mathrm{m}$. Bison outputs the mass gain and oxide thickness in the SI units of $\mathrm{kg} / \mathrm{m}^{2}$ and $\mathrm{m}$, respectively.

\subsubsection{Applicability and Uncertainty}

The chromium oxidation model selects the Leistikov correlation of zirconium-based alloys to modify. Since this correlation used over temperature ranges from $673 \mathrm{~K}$ up to $1800 \mathrm{~K}$ in Bison for zirconium-based alloy oxidation, the model for chromium is also valid within this temperature range. The oxidation behavior of chromium in water or steam environments have not been made publicly available. Thus, a large uncertainty of a factor of 2-4 is recommended. 


\section{Iron-Chromium-Aluminum (FeCrAl) Clad}

Iron-chromium-aluminum $(\mathrm{FeCrAl})$ alloys have been identified as a potentially accident tolerant cladding material because of its reduced oxidation kinetics and higher strength (larger stiffness and yield stress) [30, 31] compared to conventional zirconium-based alloys. Disadvantages include a higher thermal neutron absorption cross-section necessitating the need for a thinner cladding potentially increasing fuel cost and enrichment [31]. The following subsections include descriptions of the models available for $\mathrm{FeCrAl}$ available in Bison including their range of applicability and associated uncertainty. The alloys of interest in this work include the commercially available Kanthal APMT (APMT), and laboratory optimized alloys C06M, C35M, and C36M. All of the models in Bison for these materials are empirical in nature and therefore the uncertainty is derived from the experimental data upon which the model was created. It is desired in the future to couple lower length scale constitutive modeling from Los Alamos National Laboratory (LANL) into Bison for improved modeling of inelastic behavior including creep, plasticity, and failure. The name of the C++ class that computes the respective properties within Bison is listed in parentheses in the subsection header. The details described below can also be found in the online theory and user documentation packaged with the Bison code.

\subsection{Thermal Properties (ThermalFeCrAl)}

The ThermalFeCrAl model computes the thermal conductivity and specific heat of the following FeCrAl alloys: APMT, C06M, C35M, and C36M. The user selects their alloy prior to the analysis.

\subsubsection{Model Development}

The recent FeCrAl Handbook [32] reports the thermal conductivity is given in a general form given by:

$k=A_{1} T^{2}+A_{2} T+A_{3}$

where $A_{1}, A_{2}$, and $A_{3}$ are fitting constants tabulated in Table 12 , and $T$ is the temperature in $\mathrm{K}$.

Table 12: Coefficients used in the polynomial fit for thermal conductivity of select FeCrAl alloys

\begin{tabular}{lccc}
\hline Alloy & $\mathrm{A}_{1}\left(\times 10^{-7}\right)$ & $\mathrm{A}_{2}\left(\times 10^{-2}\right)$ & $\mathrm{A}_{3}$ \\
\hline Kanthal APMT & -7.223 & 1.5628 & 6.569 \\
C06M & 6.762 & 1.032 & 9.956 \\
C35M & -19.86 & 1.537 & 8.502 \\
C36M & -9.184 & 1.368 & 8.187 \\
\hline
\end{tabular}

The specific heat capacity correlations provided in the handbook are divided into two temperature regimes. Below the Curie Temperature $\left(T_{c}\right)$ the specific heat correlation is given by:

$C_{p}=A T+B T^{2}+C T^{3}$

where $A, B$, and $C$ are fitting constants, $C_{p}$ is the specific heat capacity in $\mathrm{J} / \mathrm{kg}-\mathrm{K}$ and $T$ is the temperature in $\mathrm{K}$. The fitting constants as well as the Curie temperature for the alloys are summarized in Table 13. It should be mentioned that the units provided for these coefficients here are different than the handbook to ensure that proper units are obtained for $C_{p}(\mathrm{~J} / \mathrm{kg}-\mathrm{K})$.

Above the Curie temperature the correlation for $C_{p}$ contains additional terms to capture the larger increase in specific heat in the 750-900 K range corresponding to a phase change of the alloys from ferromagnetic to paramagnetic. The correlation is given by:

$C_{p}=A T+B T^{2}+C T^{3}+\frac{D}{T}+E \ln \left(\frac{\left|\left(T-T_{c}\right)\right|}{T_{c}}\right)$

The fitting constants in this temperature regime are summarized in Table 14. 
Table 13: Coefficients used in the polynomial fit for specific heat of select alloys below the Curie temperature

\begin{tabular}{lcccc}
\hline Alloy & $\mathrm{A}\left(\mathrm{J} / \mathrm{kg}-\mathrm{K}^{2}\right)$ & $\mathrm{B}\left(\mathrm{J} / \mathrm{kg}-\mathrm{K}^{3} \times 10^{-3}\right)$ & $\mathrm{C}\left(\mathrm{J} / \mathrm{kg}-\mathrm{K}^{4} \times 10^{-6}\right)$ & $\mathrm{T}_{c}(\mathrm{~K})$ \\
\hline Kanthal APMT & 2.540 & -4.311 & 2.982 & 852 \\
C06M & 2.430 & -3.957 & 2.656 & 888 \\
C35M & 2.450 & -4.002 & 2.720 & 870 \\
C36M & 2.995 & -5.953 & 4.516 & 771 \\
\hline
\end{tabular}

Table 14: Coefficients used in the polynomial fit for specific heat of select alloys above the Curie temperature.

\begin{tabular}{lccccc}
\hline Alloy & $\mathrm{A}\left(\mathrm{J} / \mathrm{kg}-\mathrm{K}^{2}\right)$ & $\mathrm{B}\left(\mathrm{J} / \mathrm{kg}-\mathrm{K}^{3} \times 10^{-3}\right)$ & $\mathrm{C}\left(\mathrm{J} / \mathrm{kg}-\mathrm{K}^{4} \times 10^{-6}\right)$ & $\mathrm{D}\left(\mathrm{J} / \mathrm{kg} \times 10^{3}\right)$ & $\mathrm{E}(\mathrm{J} / \mathrm{kg}-\mathrm{K})$ \\
\hline Kanthal APMT & 1.840 & -1.843 & 0.643 & -5.712 & -50.38 \\
C06M & 1.827 & -1.807 & 0.6134 & -9.419 & -54.54 \\
C35M & 1.946 & -2.002 & 0.698 & -1.652 & -53.93 \\
C36M & 1.456 & -1.296 & 0.438 & 26.45 & -46.89 \\
\hline
\end{tabular}

\subsubsection{Applicability and Uncertainty}

The FeCrAl handbook [32] reports the temperature range of applicability for the thermal conductivity and specific heat correlations as $300 \mathrm{~K}$ to $1400 \mathrm{~K}$ and $298 \mathrm{~K}$ to $1400 \mathrm{~K}$ respectively. The uncertainty in thermal conductivity is reported as $\pm 7 \%$ for all alloys based upon the uncertainty in the experimental data available. The uncertainty in specific heat is not reported in the handbook, however, a conservative approximation of $\pm 10 \%$ is assumed based upon similar materials.

\subsection{Thermal Expansion (FeCrAlThermalExpansionEigenstrain)}

The FeCrAlThermalExpansionEigenstrain model computes the strain induced by thermal expansion for FeCrAl alloys.

\subsubsection{Model Development}

The FeCrAl handbook [32] provides a correlation for the instantaneous thermal expansion coefficient. Different coefficients apply for the alloys APMT, C06M, C35M, and C36M. This correlation is given by:

$\alpha=1.0 \times 10^{-6}\left(A_{1} T^{3}+A_{2} T^{2}+A_{3} T+A_{4}\right)$

where $\alpha$ is the instantaneous thermal expansion coefficient $A_{1}, A_{2}, A_{3}$, and $A_{4}$ are fitting constants, and $T$ is the temperature in $\mathrm{K}$. The fitting coefficients are tabulated in Table 15.

Table 15: Coefficients for instantaneous thermal expansion function for FeCrAl

\begin{tabular}{lcccc}
\hline Alloy & $A_{1}\left(\times 10^{-10}\right)$ & $A_{2}\left(\times 10^{-7}\right)$ & $A_{3}\left(\times 10^{-3}\right)$ & $A_{4}$ \\
\hline Kanthal APMT & 1.771 & 9.558 & 1.937 & 10.27 \\
C06M & 10.74 & -21.36 & 4.694 & 10.03 \\
C35M & 9.095 & -17.46 & 4.530 & 9.810 \\
C36M & 3.079 & 2.719 & 2.535 & 10.56 \\
\hline
\end{tabular}

\subsubsection{Applicability and Uncertainty}

The temperature range of applicability of the instantaneous thermal expansion correlation is reported as $293 \mathrm{~K}$ to 1500 $\mathrm{K}$ [32]. Examining all of the alloys and excluding the room temperature measurement (since the reference temperature 
of the material is also room temperature) provided in the handbook, the uncertainty in the thermal expansion coefficient ranges from 3\% to $4 \%$ over the temperature range of applicability. For $95 \%$ confidence two standard deviations is required. Therefore, the uncertainty is multiplied by two resulting in the uncertainty of the model being $\pm 8 \%$ over the temperature range of applicability.

\subsection{Elasticity (FeCrAlElasticityTensor)}

The FeCrAlElasticityTensor model computes the elastic behavior of FeCrAl alloys via the Young's modulus and Poisson's ratio. Two different models exist depending upon whether the selected alloy is the commercial APMT alloy or the laboratory optimized C06M, C35M, and C36M alloys.

\subsubsection{Model Development}

For the commercial APMT FeCrAl alloy the Young's modulus is a piecewise linear function of temperature tabulated in Table 16. The Poisson's ratio is assumed to be independent of temperature with a value of 0.3.

Table 16: Piecewise linear Young's modulus data for the commercial APMT FeCrAl alloy

\begin{tabular}{cc}
\hline Temperature (K) & Young's Modulus (GPa) \\
\hline 293.15 & 220 \\
373.15 & 210 \\
473.15 & 205 \\
673.15 & 190 \\
873.15 & 170 \\
1073.15 & 150 \\
1273.15 & 130 \\
\hline
\end{tabular}

For the laboratory optimized FeCrAl alloys C06M, C35M, and C36M the temperature dependent Young's modulus and Poisson's ratio are given by [32]:

$$
\begin{aligned}
E & =-5.46 \times 10^{-5} T^{2}-3.85 \times 10^{-2} T+199 \\
\nu & =4.46 \times 10^{-5} T+0.27
\end{aligned}
$$

where $E$ is the Young's modulus in GPa, $v$ is Poisson's ratio, and $T$ is the temperature in ${ }^{\circ} \mathrm{C}$.

\subsubsection{Applicability and Uncertainty}

The temperature range of the commercial alloy APMT is limited to the available tabulated data from $293.15 \mathrm{~K}$ to 1273.15 K. For temperatures outside this range the nearest data value is used. The uncertainty in the APMT Young's modulus and Poisson's is not provided by the manufacturer. For conservatism values of $\pm 6 \%$ and $\pm 20 \%$ are recommended for the Young's modulus and Poisson's ratio, respectively.

The temperature range for both the Young's modulus and Poisson's ratio of the laboratory optimized alloys C06M, C35M, and C36M are provided by Thompson et al. [33] as $298 \mathrm{~K}$ to $1123 \mathrm{~K}$. The FeCrAl handbook [32] provides figures of both the Young's modulus and Poisson's ratio fits to experimental data. Figure 1 illustrates the lower and upper bounds of the data provided in the handbook for the Young's modulus. A polynomial fit of the same order as the mean equation used for the model was applied to each data set as seen in the Figures. These polynomial fits represent the temperature dependent lower and upper uncertainties on the model. Figure 2(a) illustrates the mean correlation including the bounds whereas Figure 2(b) converts the temperature dependent uncertainty to a temperature dependent percent. For maximum conservatism the largest uncertainty of the lower bound can be applied to both the lower and upper bound for all temperatures resulting in an uncertainty of $\pm 6 \%$. 


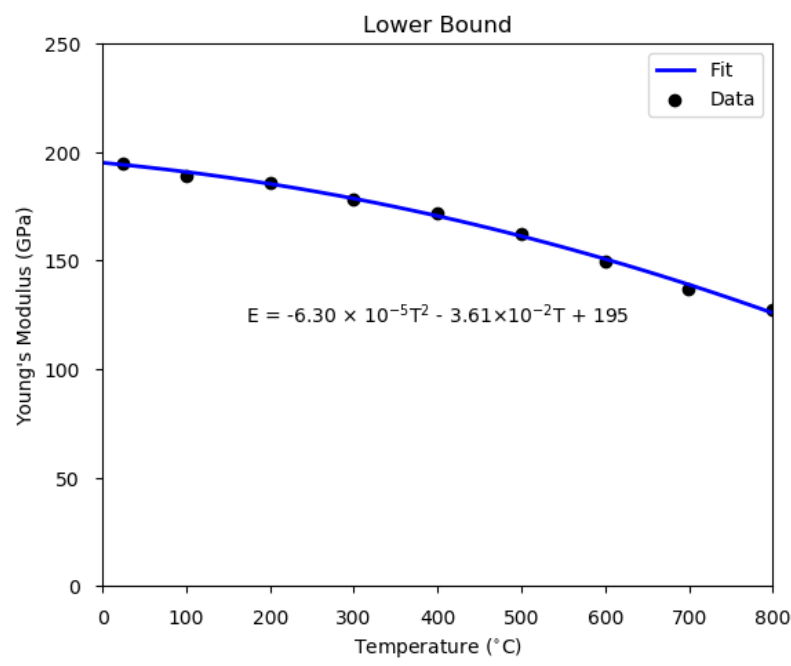

(a)

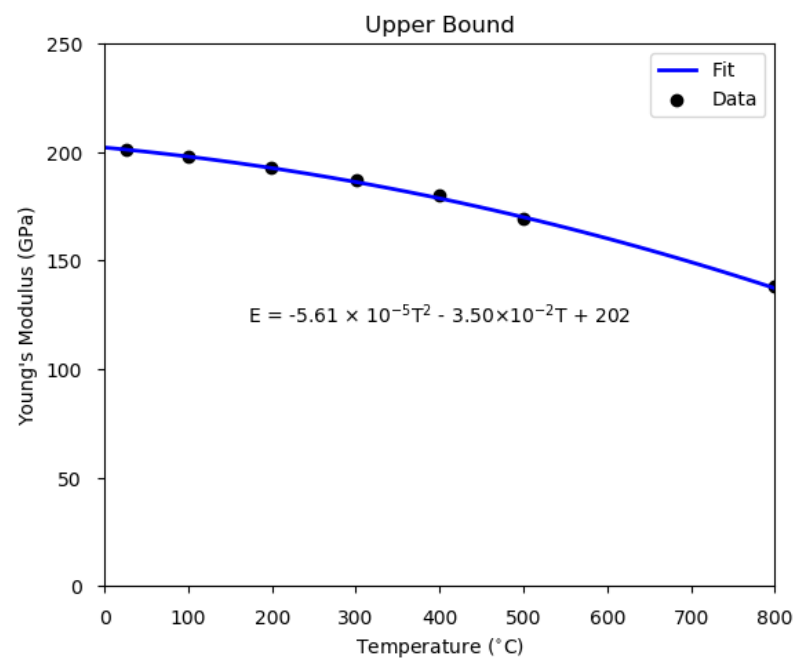

(b)

Figure 1: Quadratic fits to the (a) lower and (b) upper bounds of the experimental data for the Young's modulus of FeCrAl.

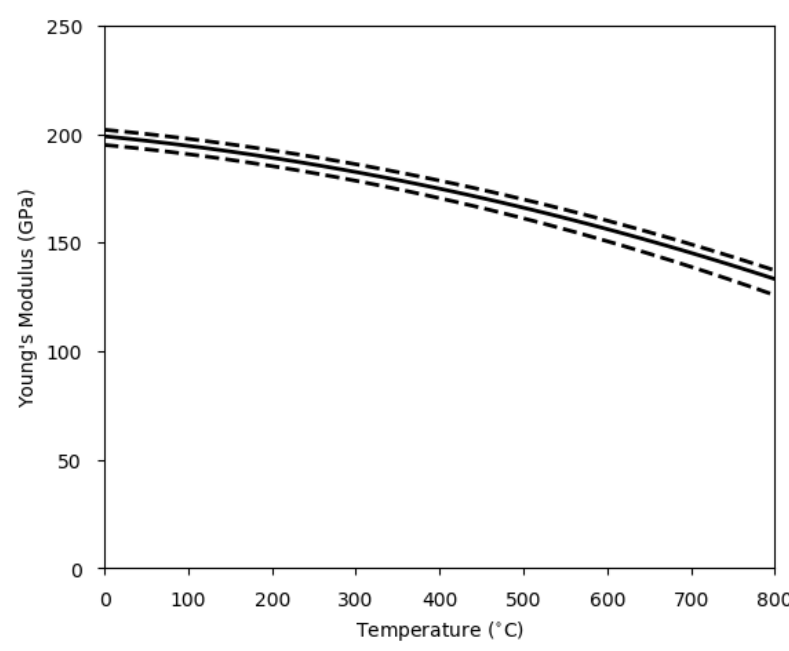

(a)

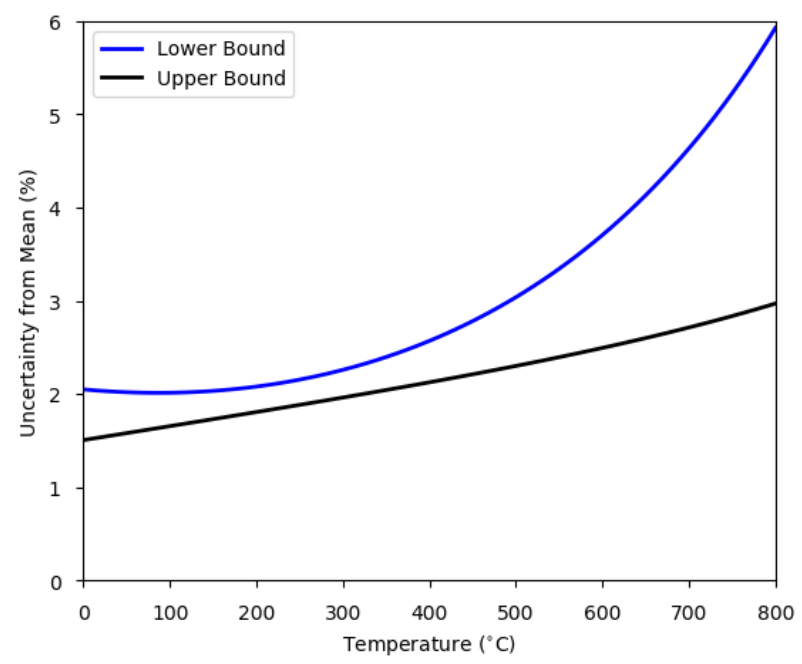

(b)

Figure 2: (a) Mean Young's modulus with associated uncertainty bands and (b) percent uncertainty as a function of temperature for the lower and upper bounds.

Similarly, for the Poisson's ratio of C06M, C35M, and C36M Figure 3 illustrates the lower and upper bounds of the data provided in the handbook. A polynomial fit of the same order as the mean equation used for the model was applied to each data set as seen in the Figures. These polynomial fits represent the temperature dependent lower and upper uncertainties on the model. Figure 4(a) illustrates the mean correlation including the bounds whereas Figure 4(b) converts the temperature dependent uncertainty to a temperature dependent percent. For maximum conservatism the largest uncertainty of the lower bound can be applied to both the lower and upper bound for all temperatures resulting in an uncertainty of $\pm 20 \%$. 


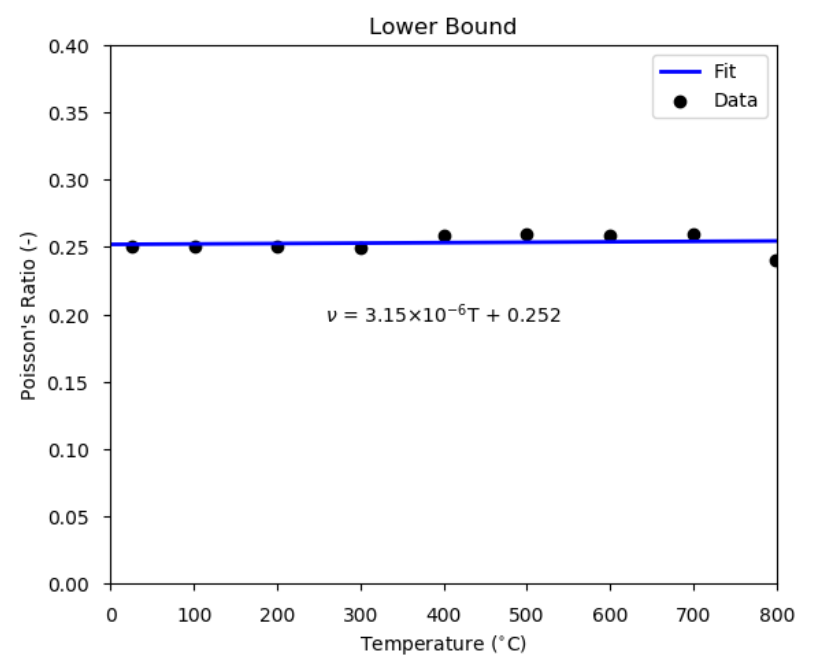

(a)

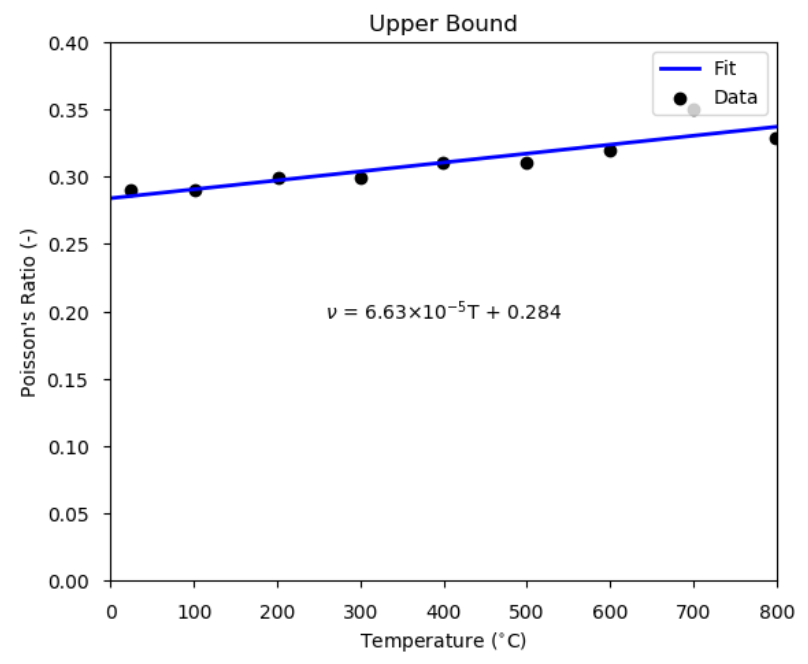

(b)

Figure 3: Linear fits to the (a) lower and (b) upper bounds of the experimental data for the Poisson's ratio of FeCrAl.

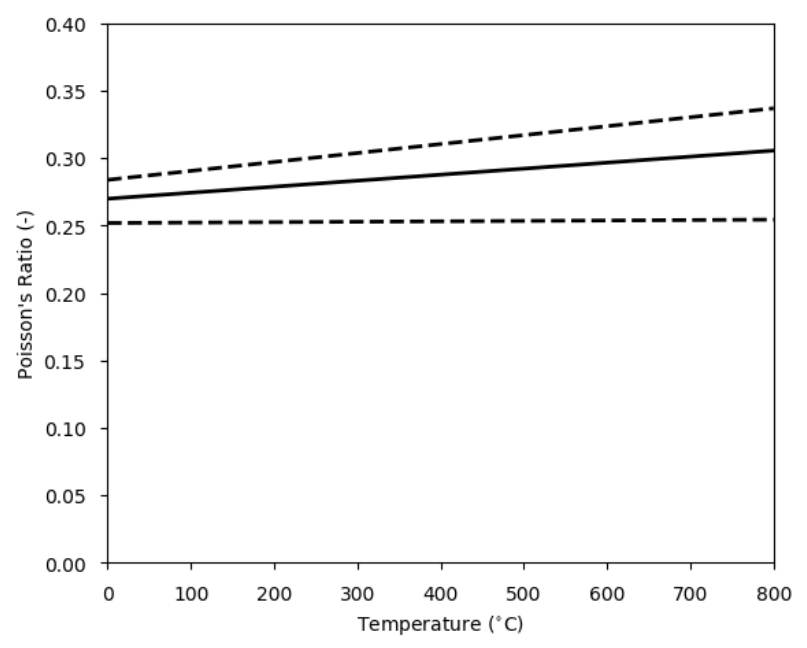

(a)

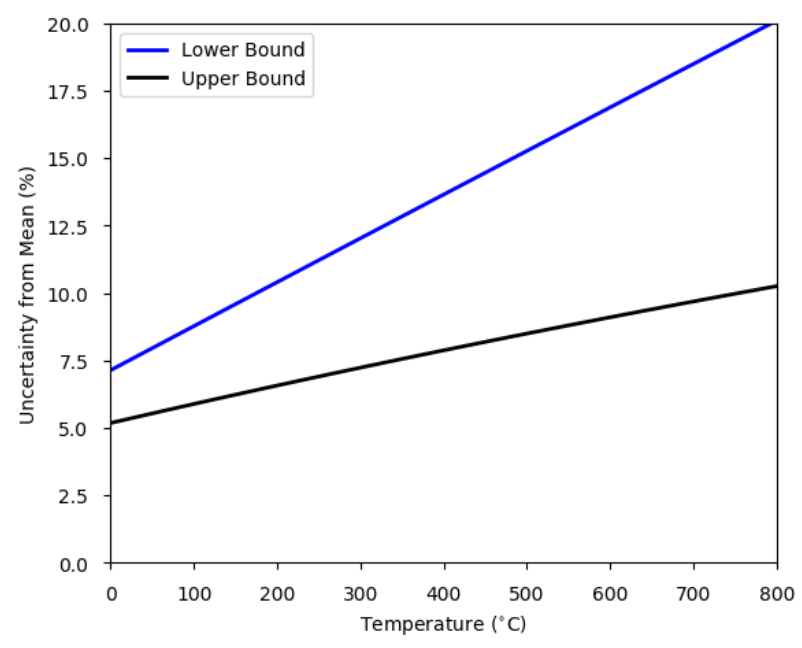

(b)

Figure 4: (a) Mean Poisson's raaiot with associated uncertainty bands and (b) percent uncertainty as a function of temperature for the lower and upper bounds.

\subsection{Thermal and Irradiation Creep (FeCrAlCreepUpdate)}

The FeCrAlCreepUpdate model computes the strains due to thermal and irradiation creep for FeCrAl alloys.

\subsubsection{Model Development}

No specific thermal creep model exists for APMT, C06M, or C36M. However, the FeCrAl handbook has reported a creep law generalized for all alloys for which a specific correlation does not exist:

$\dot{\epsilon}=2.0849 \times 10^{-43} \sigma^{7.1} \exp \left(-\frac{39208.6}{T}\right)$ 
where $\sigma$ is the effective stress in $\mathrm{Pa}$ and $T$ is the temperature in K. For C35M, [34] suggests a correlation that has two different creep laws of the Norton form depending upon the temperature regime. Below $873.15 \mathrm{~K}$ the following correlation for thermal creep is adopted

$\dot{\epsilon}=2.89 \times 10^{-36} \sigma^{5.5} \exp \left(-\frac{29709}{T}\right)$

while above $873.15 \mathrm{~K}$, the correlation proposed by [35] is employed:

$\dot{\epsilon}=5.96 \times 10^{-27} \sigma^{5.5} \exp \left(-\frac{47136}{T}\right)$

where $\dot{\epsilon}$ is the creep rate in $\mathrm{s}^{-1}, \sigma$ the effective (Mises) stress in Pa and $T$ is the temperature in K. An irradiation creep law suggested by [34] is applied to all $\mathrm{FeCrAl}$ alloys. The coefficient recommended for irradiation creep is $5 \times 10^{-6}$ per MPa per dpa. Utilizing the following conversion factor: $1 \times 10^{25} \mathrm{n} / \mathrm{m}^{2}=0.9$ dpa as suggested by [36], a correlation for irradiation creep can be derived

$\dot{\epsilon}=4.5 \times 10^{-31} \sigma \phi$

where $\sigma$ is the effective stress in MPa and $\phi$ is the fast neutron flux in $\mathrm{n} / \mathrm{m}^{2}$-s.

\subsubsection{Applicability and Uncertainty}

The applicability of the thermal creep models for APMT, C06M, C35M, and C36M is for temperatures ranging from $623 \mathrm{~K}$ to $1473 \mathrm{~K}$ and stresses ranging between 1 and $150 \mathrm{MPa}$. For the irradiation creep model, its applicability includes all normal operating conditions of a typical LWR. The uncertainty in the models are not provided in the FeCrAl handbook, however, the models are described as highly generalized and given that the uncertainty in well studied materials (e.g., Zircaloy-4) is on the order of $20 \%$ a conservative uncertainty of $\pm 30 \%$ is recommended for both the thermal and irradiation creep models for all $\mathrm{FeCrAl}$ alloys.

\subsection{Irradiation Swelling (FeCrAlVolumetricSwellingEigenstrain)}

The FeCrAlVolumetricSwellingEigenstrain model computes the strain introduced due to possible irradiation induced swelling in $\mathrm{FeCrAl}$ alloys.

\subsubsection{Model Development}

As an approximation a simplistic model provided in [34] has been implemented in Bison. The maximum estimated swelling rate is $0.05 \%$ per dpa. Using the same conversion factor from dpa to fluence as in the irradiation creep model, the volumetric swelling strain rate is given by:

$\dot{\epsilon}_{\text {swell }}=4.5 \times 10^{-29} \phi$

Integrating over time the volumetric swelling is given by

$\epsilon_{\text {swell }}=4.5 \times 10^{-29} \Phi$

where $\Phi$ is the fast neutron fluence given in $\mathrm{n} / \mathrm{m}^{2}$.

\subsubsection{Applicability and Uncertainty}

The irradiation induced swelling model is applicable for normal operating conditions of a typical LWR. The uncertainty associated with the model corresponds to a range of zero irradiation induced swelling strain to the maximum value reported by Equation 50. 


\subsection{Plasticity (FeCrAlPlasticityUpdate)}

The FeCrAlPlasticityUpdate model computes the inelastic strain due to instantaneous plasticity for FeCrAl clads. The model is applied used for all alloys available in Bison.

\subsubsection{Model Development}

The yield stress (YS) as a function of temperature is a piecewise linear function based upon the experimental data of [37]. However, the data of [37] only covers temperatures ranging from 300 to $1000 \mathrm{~K}$. Based on research by [38] on other ferritic and martensitic steels, there are distinct temperature dependent regions (low, mid, high) of the ultimate tensile strength (UTS). In the low temperature region the UTS drops relatively slowly with increasing temperature. In the midrange temperatures there is a rapid decrease in the UTS as temperature increases. The high temperature region results in a slow reduction of the UTS to approximately zero at the melting point. From the available data on FeCrAl alloys, the low and mid temperature regions are captured. To mimic the observations of [38] an additional data point of a UTS of zero was added to Yamamoto's data at the melting point of FeCrAl alloys (1773 K). Since the yield stress approaches the UTS at midrange temperatures (See Figure 5), the yield stress is also set to zero at the melting point.

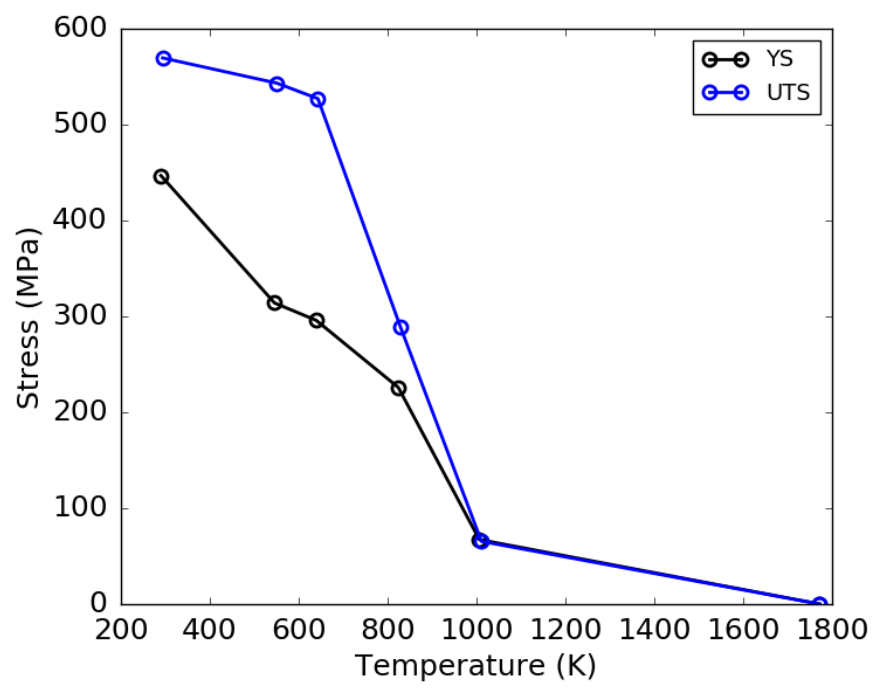

Figure 5: Yield Stress and Ultimate Tensile Strength as a function of temperature for FeCrAl. The UTS and YS is set to zero at the melting point $\sim 1773.0 \mathrm{~K}$.

\subsubsection{Applicability and Uncertainty}

The instantaneous plasticity model for $\mathrm{FeCrAl}$ is applicable from $290 \mathrm{~K}$ up to $1773 \mathrm{~K}$. The model was derived from yield stress measurements of a single $\mathrm{FeCrAl}$ alloy. Given that the model is applied to multiple alloys that may have a wider range of variation (measurements do not exist for C06M and C36M) a conservative uncertainty of $\pm 25 \%$ is included for the yield stress.

\subsection{Oxidation Kinetics (FeCrAlOxidation)}

The material FeCrAlOxidation model computes the oxide scale thickness and mass gain of FeCrAl clads. Experimental tests of various FeCrAl alloys were completed by [39] at normal reactor operating temperatures in PWR and BWR water conditions. Both hydrogenated BWR and normal BWR water chemistry was investigated. Of interest for the Bison model is the PWR and BWR-Normal Water Chemistry (NWC) oxidation cases. 
The oxide mass gain is calculated by:

$w_{1}=k_{1} \sqrt{t}$

where $k_{1}$ is the parabolic rate constant in units of $\mathrm{mg} \mathrm{cm}^{-2} \mathrm{~h}^{1 / 2}$ and $t$ is the time in hours. For generality the average value of $k_{1}$ computed by [39] is used and depends upon the water chemistry. For PWR, $\mathrm{k}_{1}=3.49 \times 10^{-3} \mathrm{mg} \mathrm{cm}^{-2} \mathrm{~h}^{1 / 2}$ and for BWR, $\mathrm{k}_{1}=3.46 \times 10^{-4} \mathrm{mg} \mathrm{cm}^{-2} \mathrm{~h}^{1 / 2}$. To be consistent with Bison's SI units the value of $k_{1}$ is multiplied by a conversion factor to change the units to $\mathrm{kg} \mathrm{m}^{-2} \mathrm{~s}^{1 / 2}$. Once the mass gain is known in SI units the oxide thickness is calculated by:

$x=\frac{w_{1}}{\rho_{\text {oxide }}}$

where $\rho_{\text {oxide }}$ is the density of the oxygen in the chromite oxide layer that is formed, and $\mathrm{x}$ is the oxide thickness in meters. The density of oxygen in the chromite layer is taken as $1440 \mathrm{~kg} / \mathrm{m}^{3}$ [39]. The Bison model does not take into account the iron dissolution that results in mass loss as the fuel performance metric of interest is the oxide layer thickness.

\subsubsection{Applicability and Uncertainty}

The oxidation model for FeCrAl available in Bison is only applicable for normal operating conditions in both PWR and BWR water chemistries. The uncertainty in the rate constant for oxide growth is computed as two times the standard deviation of the limited number of measurements from [39]. For PWR water chemistry the rate constant is given as $(3.49 \pm 2.54) \times 10^{-3}$. For BWR-NWC the rate constant is given as $(3.46 \pm 2.68) \times 10^{-4}$.

\subsection{Failure (FeCrAlCladdingFailure)}

A failure model was developed by the author of this report for FeCrAl alloys (See [2] for a full derivation) and is captured by the FeCrAlCladdingFailure model and applied to APMT, C06M, C35M, and C36M.

\subsubsection{Model Development}

The failure model is stress based developed from the experimental work of [40]. The model consists of an exponential fit to the experimental data. At the point where the fit crosses the UTS curve provided in Figure 5 is the temperature at which the burst stress $\left(\sigma_{\text {burst }}\right)$ transitions from the UTS to the fit. Therefore, the combined equation is given by:

$\sigma_{\text {burst }}= \begin{cases}\text { Ultimate Tensile Strength, } & \text { for } T \leq 796.8 \mathrm{~K} \\ 28440.98 \mathrm{e}^{-0.005588 T}, & \text { for } T>796.8 \mathrm{~K}\end{cases}$

\subsubsection{Applicability and Uncertainty}

The range of applicability of the model spans temperatures from $298 \mathrm{~K}$ and to $1773 \mathrm{~K}$. The model is based upon the only burst tests of $\mathrm{FeCrAl}$ at the time of development. Given the desire to apply the model under other burst like conditions an uncertainty must be applied. Under different experimental conditions the times and temperature at burst may vary. Therefore, in absence of additional experimental data an uncertainty of $\pm 25 \%$ is recommended for the calculated value of $\sigma_{\text {burst }}$.

\subsection{Tritium Permeability}

A finite difference model developed by $\mathrm{Hu}$ et al. [41] for tritium has been adapted for use within the finite element method in Bison. 


\subsubsection{Model Development}

The model considers the production of tritium in the fuel, release to the plenum, pickup at the interior surface of the clad and diffusion through the clad to coolant. Implementation of the model required the development of three different Bison models including TritiumProduction a postprocessor, TritiumPermeability a material property, and TritiumPermeabilityBC a flux boundary condition.

Tritium is produced as a fission product from irradiation of $\mathrm{UO}_{2}$. A portion of this tritium is released to the fuel-toclad gap and is able to be picked up by the clad and diffuse through to the coolant. This postprocessor calculates the concentration of tritium available in the fuel-to-clad gap for pickup by the clad as a function of time. According to [41] the tritium concentration $\left(T_{g}(t)\right)$ within the fuel-to-clad gap can be expressed by:

$\frac{d T_{g}(t)}{d t}=Q_{s}-Q_{g-c}-\lambda T_{g}(t)$

where $Q_{s}$ is the production rate of tritium from the fuel in $\mathrm{mol} / \mathrm{m}^{3}-\mathrm{s}, Q_{g-c}$ is the rate of absorption of tritium by the clad internal surface, and $\lambda$ is the decay constant of tritium. It is assumed that the tritium released from the fuel to fuel-to-clad gap is immediately distributed homogeneously within the gap. Thus, one arrives at:

$J_{g-i}=a Q_{g-c}=a\left(\frac{d T_{g}(t)}{d t}-Q_{s}+\lambda T_{g}(t)\right)$

where $a$ is the ratio of the fuel-to-clad gap volume to the inner clad surface area. The flux from the gap to clad interface into the clad bulk at which this flux boundary condition is applied is given by:

$J_{i-c}=-D \frac{\partial T_{c}(0, t)}{\partial x}$

where $J_{i-c}$ is the flux of tritium into the clad in $\mathrm{mol} / \mathrm{m}^{2}-\mathrm{s}, D$ is the diffusion coefficient of tritium in the clad material $\mathrm{m}^{2} / \mathrm{s}$, and $T_{c}(0, t)$ is the concentration of tritium at the clad inner surface as a function of time in $\mathrm{mol} / \mathrm{m}^{3}$. Based on Sievert's law, the tritium concentration at the clad inner surface is proportional to $p^{1 / 2}$, where $p$ is the partial pressure of tritium in the fuel-to-clad gap. The tritium partial pressure in the gap is related to the concentration of tritium in the gap through the ideal gas law. Therefore, one can relate the tritium concentration at the clad inner surface to the tritium concentration in the gap through

$T_{c}(0, t)=S p^{1 / 2}=S \sqrt{R T_{g a p} \cdot T_{g}(t)}$

where $S$ is the solubility of tritium in the clad in $\mathrm{mol} / \mathrm{m}^{3}-\mathrm{Pa}^{1 / 2}, R$ is the ideal gas constant taken as $8.3145 \mathrm{~J} / \mathrm{mol}-\mathrm{K}$, $T_{g a p}$ is the temperature of the fuel-to-clad gap in $K$, and $T_{g}(t)$ concentration of tritium in the fuel-to-clad gap in $\mathrm{mol} / \mathrm{m}^{3}$. By substituting Equation 57 into Equation 56, substituing $S=\frac{\phi_{T}}{D}$, and performing the appropriate differentiation one arrives at the following for the flux boundary condition at the inner surface of the clad:

$J_{i-c}=-\sqrt{R T_{g a p} \cdot T_{g}(t)} \frac{d \phi_{T}}{d T} \frac{d T}{d x}$

where $\phi_{T}$ is the tritium permeability of the clad in mol/m-s- $\mathrm{Pa}^{1 / 2}, \frac{d}{d T}$ is the derivative with respective to temperature operator (applied to $\phi_{T}$ ) and $\frac{d T}{d x}$ is the temperature gradient at the interface. As per [41] local equilibrium is assumed at the clad inner surface meaning that the flux from the fuel-to-clad gap into the clad inner surface is equal to flux into the clad bulk (i.e, $J_{g-i}=J_{i-c}$ ). Equating Equation 55 and Equation 58 one arrives at

$-\sqrt{R T_{\text {gap }} \cdot T_{g}(t)} \frac{d \phi_{T}}{d T} \frac{d T}{d x}=a\left(\frac{d T_{g}(t)}{d t}-Q_{s}+\lambda T_{g}(t)\right)$

The above equation is then rearranged as follows:

$\left(d T_{g}(t)-Q_{s} d t+\lambda T_{g}(t)\right) d t+\frac{\sqrt{R T_{g a p} \cdot T_{g}(t)}}{a} \frac{d \phi_{T}}{d T} \frac{d T}{d x} d t=0$ 
where $d T_{g}(t)=T_{g}(t)-T_{g}(t)_{\text {old }}$ and $d t$ is the current timestep size. The production rate of tritium from the fuel is calculated by:

$Q_{s}=Q_{s_{\text {old }}}+\frac{y_{t} f \dot{\phi}_{\text {avg }}}{N_{A}}$

where $Q_{s_{\text {old }}}$ is the production rate of tritium from the previous timestep, $y_{t}$ is the cumulative yield fraction of tritium (default value of $1.08 \times 10^{-4}$ ), $f$ is the fraction of tritium produced in the fuel immediately released to the fuel-to-clad gap (default value of 0.5 or $50 \%), \dot{\phi}_{\text {avg }}$ is the average fission rate over the timestep given by:

$\dot{\phi}_{\text {avg }}=\frac{\dot{\phi}+\dot{\phi}_{\text {old }}}{2}$

where $\dot{\phi}$ is the current fission rate and $\phi_{\text {old }}$ is the fission rate from the previous timestep. The decay constant of tritium is given by:

$\lambda=\frac{\ln (2)}{t_{1 / 2}}$

where $t_{1 / 2}$ is the half-life of tritium $\left(3.885 \times 10^{8} \mathrm{~s}(12.32\right.$ years $\left.)\right)$. Equation 60 is solved for $T_{g}(t)$ through an iterative process with the initial guess for a timestep taken as $T_{g}(t)_{\text {old }}$. For the first timestep the initial guess is zero. In general, the permeability $(\phi)$ is defined as the product of the diffusion coefficient $(D)$ and the solubility $(S)$ of the diffusing species. Given the difficulty of working with tritium, experiments are typically conducted that determine the hydrogen permeability through a material. The permeability of hydrogen $\left(\phi_{H}\right)$ has an Arrhenius general form given by:

$\phi_{H}=\phi_{0} \exp \left(-\frac{E}{R T}\right)$

where $\phi_{0}$ is the permeability coefficient, $E$ is the apparent activation energy for permeation in $\mathrm{J} / \mathrm{mol}$, which is essentially the sum of the activation energies for dissolution and diffusion [41], $R$ is the gas constant and $T$ is the temperature in $\mathrm{K}$. The units of permeability for hydrogen is $\mathrm{mol} / \mathrm{m}-\mathrm{s}-\mathrm{Pa}^{1 / 2}$. Once the hydrogen permeability of a material is known, the tritium permeability can be calculated from the inverse ratio of the square root of the masses of the isotopes through [42]:

$\phi_{T}=\frac{1}{\sqrt{3}} \phi_{H}$

where $\phi_{T}$ is the permeability of tritium. For FeCrAl, the values for APMT are taken from [41] where $\phi_{0}=(9.77 \pm 2.23) \times$ $10^{-7} \mathrm{~mol} / \mathrm{m}-\mathrm{s}-\mathrm{Pa}^{1 / 2}$ and $E=71800 \pm 5800 \mathrm{~J} / \mathrm{mol}$.

\subsubsection{Applicability and Uncertainty}

The tritium permeability model is valid for temperatures ranging from $623 \mathrm{~K}$ to $923 \mathrm{~K}$. This temperature range coincides with the range over which experimental measurements were made for the hydrogen permeability in $\mathrm{FeCrAl} \mathrm{[41].}$ Uncertainty in the model occurs through the reported uncertainty in the permeability coefficient and activation energy in the hydrogen permeability material property portion of the model. The uncertainties are therefore $\pm 22.8 \%$ and $\pm 8.1 \%$ for the leading coefficient and activation energy respectively. 


\section{Bison Demonstration Cases}

Experimental data in the open literature for the behavior of Cr-coated zirconium-based and FeCrAl clads is scarce. What data is available has been used to develop the correlations for the models available in Bison and thus cannot be used for validation. In absence of other data the Bison capability of simulating these ATF cladding concepts is assessed through qualitative comparisons to traditional clads under identical operating conditions. Normal operating behavior has been assessed in detail by Gamble et al. [2] and Wagih et al. [24]. Here, the focus is on behavior during LOCA like conditions using the latest models for $\mathrm{Cr}$-coated and $\mathrm{FeCrAl}$ clads as well as verifying the tritium behavior reported by Hu et al. [41] in FeCrAl.

\subsection{Cr-coated Clad Ballooning Behavior}

It has been postulated that that under LOCA conditions in addition to the coating mitigating rapid oxidation a more coolable geometry is maintained. This is because the coated tubes experience less cladding distention (ballooning) then their uncoated counterparts. However, no experimental evidence has been made public to support these reduced balloon size claims. In the absence of experimental data, a postulated burst experiment was conducted to investigate whether or not the claim of reduced distention in Cr-coated clad tubes can be verified.

The approach taken in this work is similar to that in experimental tests that have been completed to evaluate clad tube burst behavior [40]. Here, $0.25 \mathrm{~m}$ long clad tubes with $8.36 \mathrm{~mm}$ inner diameter and $0.57 \mathrm{~mm}$ thickness were used as the bare uncoated tube dimensions. A variety of model parameters were varied to identify correlations between the parameters and corresponding time to failure including the coating thickness, substrate material, pressure ramp rate, peak clad temperature, and fast neutron fluence. The values of the parameters used in this study are summarized in Table 17.

Table 17: The parameters varied in the Cr-coated versus uncoated clad balloon parametric study.

\begin{tabular}{lc}
\hline Model Parameter & Values \\
\hline Coating thickness $(\mu \mathrm{m})$ & $0,10,20,50,100$ \\
Substrate Material & $\mathrm{M} 5^{\circledR}, \mathrm{ZIRLO}^{\mathrm{TM}}$, Zircaloy-4 \\
Pressure Ramp Rate $(\mathrm{kPa} / \mathrm{s})$ & $5,10,20$ \\
Peak Clad Temperature $(\mathrm{K})$ & $900,1000,1100,1200$ \\
Fast Fluence $\left(\times 10^{25} \mathrm{n} / \mathrm{m}^{2}\right)$ & $0,2.5,5$ \\
\hline
\end{tabular}

Initially, the tubes are subjected to an interior and exterior pressure of $101.325 \mathrm{kPa}$ and a temperature of $300 \mathrm{~K}$. Over the first 10000 seconds of the simulation the tubes are brought to a sinusoidal temperature profile that is held constant during the transient phase of the analysis. The sinusoidal temperature profile in $\mathrm{K}$ is given by:

$T(y)=T_{\text {peak }}-20.0\left(1.0-\sin \left(\frac{\pi y}{0.25448}\right)\right)$

where $T_{\text {peak }}$ is the peak clad temperature and $y$ is the axial position along the tube. The peak temperature occurs at the tube midplane and the $20 \mathrm{~K}$ variation between the midplane to the tube ends preferentially induces ballooning at the midplane of the tube. After the temperature profile is established the linear pressure ramp begins.

Numerous failure criteria exist in the literature for Zircaloy materials (See Section 2.7), but none currently exist for pure chromium. Therefore, a failure criterion that is independent of the materials needs to be used to terminate the simulation. Thus, in this work the overstrain criterion, which defines failure when the inelastic true strain in the hoop direction exceeds a value of $33.6 \%$, was selected.

All combinations of in Table 17 were analyzed with the results of each substrate separated into different figures. Each uncoated study for the Zircaloy-4, M5 ${ }^{\circledR}$ and ZIRLO ${ }^{\mathrm{TM}}$ substrates resulted in 36 simulations. Including the variation of coating thickness in a separate coating study for each substrate resulted in 144 analyses for each substrate. Therefore, in total 540 simulations were performed. By utilizing discrete values for the input parameters a multidimensional parameter study was performed by coupling Bison to the Dakota [43] software. The results of a multidimensional 
parameter study are best visualized in main effects plots as shown in Figures 6 through 8. Main effects plots provide insight into the input parameters that have the greatest influence on the output parameter of interest while taking into account all of the other inputs. In addition, correlations between inputs and outputs can be identified.

In this work, the end time of the simulation is chosen as the output metric of interest as it is correlated to the size of the balloons observed in the tubes. Since the failure criterion is based on inelastic strain, the maximum clad diameter will be similar in the coated and uncoated tubes at failure. However, if the time taken to achieve failure is longer in coated tubes, one can argue that at any given time the balloon size is smaller than the uncoated tubes. The end time is defined as the time to failure from the time the pressure ramp begins.

Figure 6 presents the main effects plots for the uncoated and coated Zircaloy-4 tubes. To read the main effects plot one must understand its format. The vertical axis corresponds to the mean value of the output metric of interest (in this case the end time from the start of the pressure ramp). Each panel from left to right corresponds to a single input parameter where the $\mathrm{x}$-tick labels correspond to the permissible values of the input in the study as provided in Table 17. The solid dots on the lines in the panels correspond to the mean value of all simulations for which the input parameter was the specified value. For example, in the uncoated case for the peak cladding temperature the time to failure for all cases with a value of $900 \mathrm{~K}$ was $1356 \mathrm{~s}$ from the start of the pressure ramp. The dashed line through all panels represents the mean value of all cases studied for that substrate. Recall that the uncoated case had 36 simulations and the coated case had 144 simulations for each of the cladding substrates.

In both the uncoated and coated cases, the end time of the simulation was negatively proportional to the peak cladding temperature and pressure ramping rate. As these two inputs were increased the mean time to failure rapidly decreased as expected. The impact of coating thickness showed a small but positive correlation. Practical no correlation between the input initial fast neutron fluence and the end time was found.

Identical behavior was found for the tubes with $\mathrm{ZIRLO}^{\mathrm{TM}}$ as the substrate as shown in 7 . This is because the primary difference in the mechanical properties of the Zircaloy alloys of interest is the cold work identified in Table 5. Since Zircaloy- 4 and ZIRLO ${ }^{\mathrm{TM}}$ have the same cold work, the behavior of the tubes are identical. It should be noted that the oxidation behavior of the various zirconium-based substrates are also different but the kinetics of the ZIRLO ${ }^{\mathrm{TM}}$ and $\mathrm{M} 5^{\circledR}$ are to the best of the author's knowledge not publicly available and therefore could not be included in the uncoated tube analysis in this work. It is expected that including oxidation effects would show substantial differences between the uncoated results of the different substrates. The results for the coated cases would likely be unaffected as the oxidation kinetics of chromium is assumed to be at least an order of magnitude less than Zircaloy-4. However, since oxidation is ignored in all cases the trends observed should be the consistent between coated and uncoated tubes. Minor differences are observed in the behavior of the M5 ${ }^{\circledR}$ when comparing to Zircaloy-4 and ZIRLO ${ }^{\mathrm{TM}}$ entirely driven by the difference in cold work.

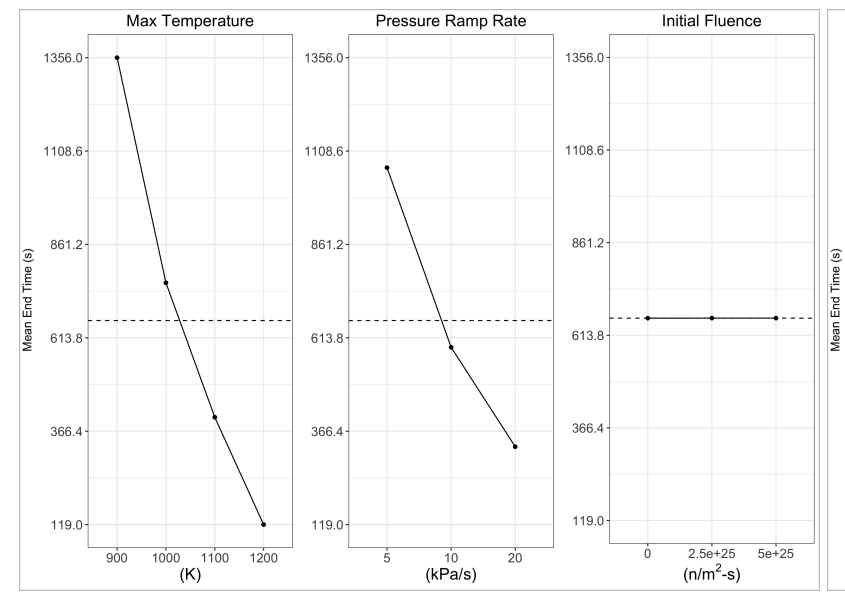

(a)

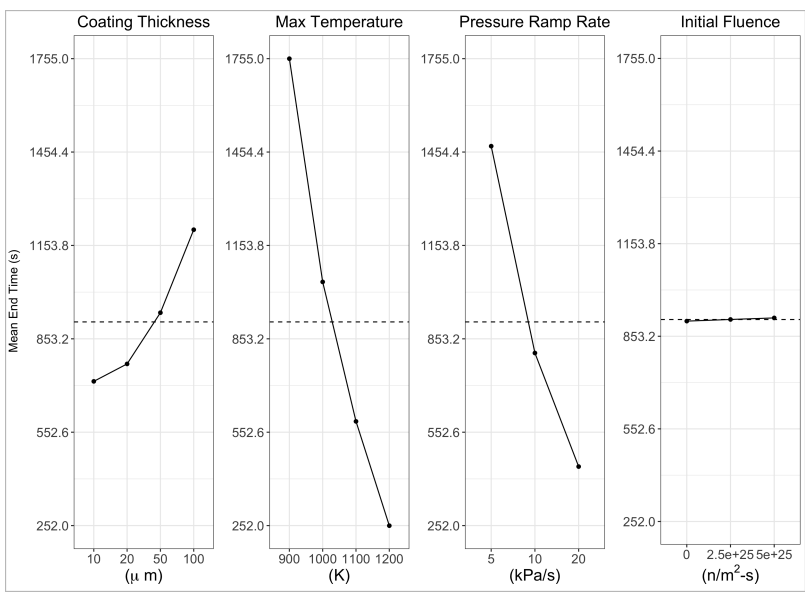

(b)

Figure 6: Main effects results for (a) uncoated and (b) Cr-coated Zircaloy-4 clad tubes. 

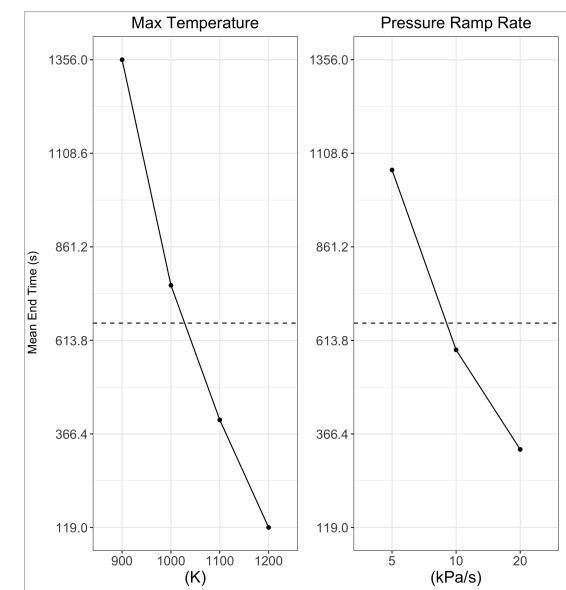

(a)

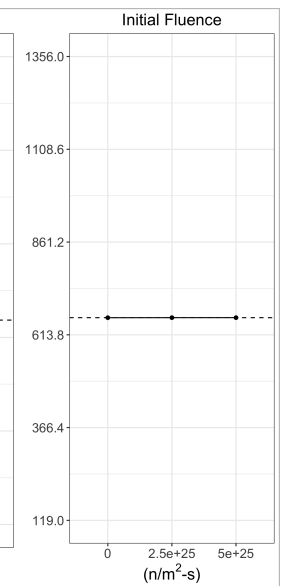

$\left(n / m^{2}-s\right)$

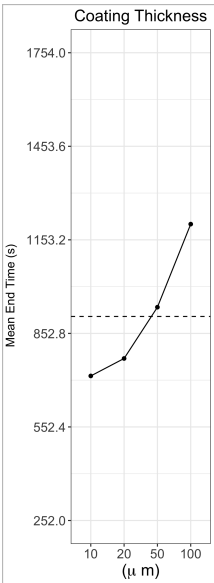

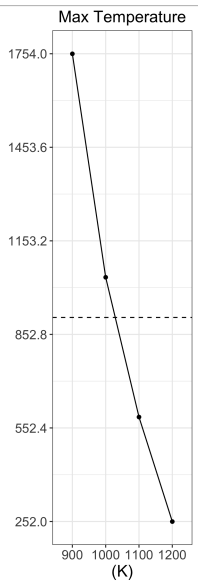

(b)

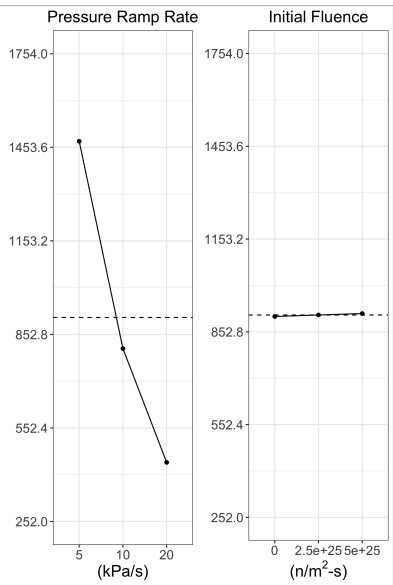

Figure 7: Main effects results for (a) uncoated and (b) Cr-coated ZIRLO ${ }^{\mathrm{TM}}$ clad tubes.

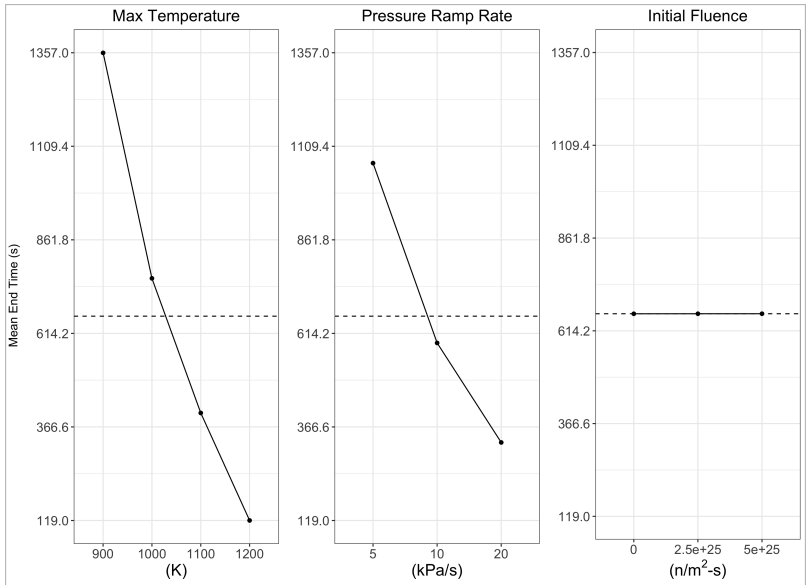

(a)

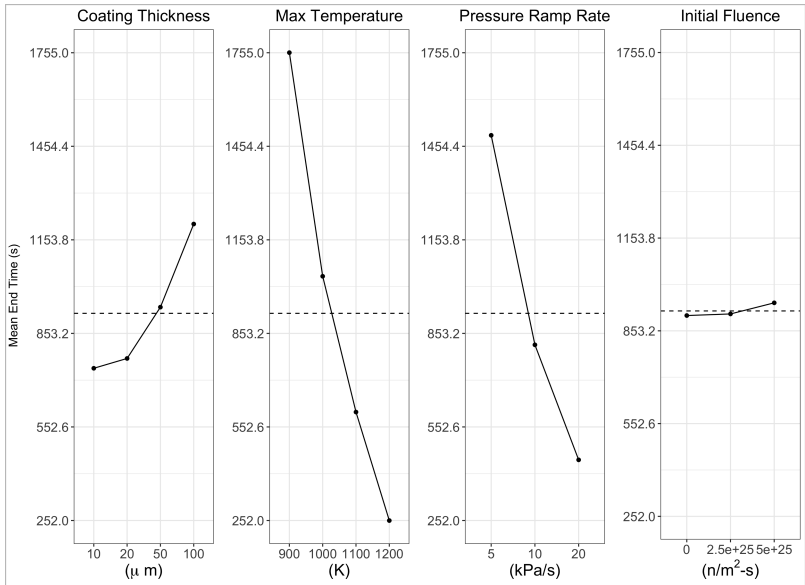

(b)

Figure 8: Main effects results for (a) uncoated and (b) Cr-coated M5 ${ }^{\circledR}$ clad tubes.

Based upon the results of this simple numerical experiment it has been observed that the time to reach the limiting inelastic hoop strain is longer in the coated cases for all substrates effectively confirming the postulated claim that Cr-coated clad tubes have smaller balloons at any given time. The cause of the reduced balloons in Cr-coated tubes can be attributed to the increased tube thickness due to the presence of the coating making the tube stiffer as well as large interface stress due to the mismatch in thermal expansion coefficients causing yielding of the coating. The yielding of the coating causes strain hardening increasing the overall strength of the tube, which requires a higher pressure to deform the same distance as an uncoated tube. Quantitative comparisons should be completed once the experimental data supporting these claims become publicly available.

\subsection{FeCrAl Clad Behavior}

The thermo-mechanical behavior of FeCrAl under normal operating conditions has been studied extensively by [2, 44]. From an accident tolerance point of view, the behavior of FeCrAl during postulated transients is more important. In addition, one of the potential disadvantages of $\mathrm{FeCrAl}$ is the increased amount of tritium released from the fuel rods. This phenomenon was investigated by [41] and the model has been generalized for use in Bison. A verification study 
is also performed that exercises the FeCrAl permeability model.

\subsubsection{Ballooning and Rupture}

The ballooning and rupture behavior of $\mathrm{FeCrAl}$ tubes was previously investigated by Gamble et al. [2] by subjecting $\mathrm{FeCrAl}$ tubes to known LOCA-like conditions under oxidizing and non-oxidizing environments from experiments completed on Zircaloy-4 tubes. The results indicated that the burst behavior of FeCrAl was similar to Zircaloy-4. In the time since that publication, the $\mathrm{FeCrAl}$ material models in Bison have been updated to include the latest correlations from the FeCrAl handbook (See Chapter 4) including new alloys C06M and C36M. Therefore, in this work, the nonoxidizing cases from the PUZRY [45] test series are revisited using the latest models.

The PUZRY tests consisted of experiments focused on investigating the ballooning behavior of Zircaloy- 4 claddings to provide validation data for fuel performance models. In these experiments, tube samples were analyzed under isothermal conditions in the temperature range of $973-1473 \mathrm{~K}$ in a resistance furnace. The inner pressure of the test tube was increased linearly until burst of the sample. The specimens were $50 \mathrm{~mm}$ long with inner and outer diameters of 9.3 and $10.75 \mathrm{~mm}$, respectively. The specimen was placed in a quartz test tube filled with inert argon gas, and heated up in an electrical furnace. The pressure of the inert gas in the quartz tube was kept constant at 0.1 MPa. After an approximately $1000 \mathrm{~s}$ heat-up period, the sample was pressurized with argon gas at a constant pressurization rate. Pressurization rates between $7 \times 10^{-4}$ and $2.6 \times 10^{-2} \mathrm{MPa} / \mathrm{s}$ were tested. Since the gas on the exterior of the specimens was inert, oxidation effects were not considered. In total, the experiment included 31 ballooning tests.

Applying these experimental conditions to $\mathrm{FeCrAl}$ rodlets and comparing to the Zircaloy-4 experimental data can provide insight into the pressure at burst for $\mathrm{FeCrAl}$ clads for the same operating conditions. Six ballooning tests from the PUZRY series were selected to be modeled. The choice was based upon the selected rods used by the Fuel Modelling under Accident Conditions (FUMAC) benchmark of the IAEA [46]. Details of the selected experiments are summarized in Table 18.

Table 18: Conditions of the selected PUZRY experiments.

\begin{tabular}{ccc}
$\begin{array}{c}\text { Rod } \\
\text { Number }\end{array}$ & $\begin{array}{c}\text { Temperature } \\
(\mathrm{K})\end{array}$ & $\begin{array}{c}\text { Pressure Ramp } \\
\text { Rate }(\mathrm{MPa} / \mathrm{s})\end{array}$ \\
\hline 8 & 1274.15 & 0.00763 \\
10 & 1375.75 & 0.00710 \\
12 & 1470.85 & 0.00723 \\
18 & 1173.35 & 0.01151 \\
26 & 971.55 & 0.01193 \\
30 & 1073.55 & 0.02630 \\
\hline
\end{tabular}

In these experiments the cladding thickness was $725 \mu \mathrm{m}$ which is 1.26 times greater than the current thickness $(575$ $\mu \mathrm{m}$ ) of Zircaloy-4 used in LWRs. To facilitate meaningful comparisons FeCrAl tubes with a thickness of $\sim 485 \mu \mathrm{m}$ were subject to the experimental conditions and compared to the measured behavior of Zircaloy- 4 . A $\sim 485 \mu \mathrm{m}$ thick cladding was modeled because it is 1.26 times greater than the FeCrAl thickness $(\mu \mathrm{m})$ expected for use in current LWRs.

To model the cladding tubes two-dimensional axisymmetric models were created. Five QUAD4 elements were used through the cladding thickness. Heating was simulated by a Dirichlet temperature boundary condition applied to the tube outer wall, considering a $1000 \mathrm{~s}$ heat-up period and isothermal conditions afterwards [45]. An axial temperature gradient was considered to allow for the temperature gradients present in the furnace [47]. The maximum temperature is applied at the specimen midplane, consistent with experimental observations of localized ballooning at the midplane. A maximum temperature variation of $6 \mathrm{~K}$ along the specimen was considered [47]. In absence of detailed axial temperature profiles, a linear profile was adopted. Increasing pressure was applied at the tube inner wall at the experimental pressurization rate. Taking advantage of the symmetry of the problem, only the lower half of the heated clad length was modeled.

The pressure at burst for the different $\mathrm{FeCrAl}$ alloys are shown along with the Zircaloy- 4 experimental measurements in Figure 9. At higher temperatures the burst stress required to fail the tube is found to be larger in the $\mathrm{FeCrAl}$ alloys 
whereas at lower temperatures the $\mathrm{FeCrAl}$ tubes tend to fail at the same pressure or slightly earlier than the Zircaloy-4 clads. Between the different alloys, C35M consistently fails earlier at all temperatures compared to APMT, C06M, and C36M. This difference is attributed to the different creep models for the alloys. From Section 4.4 it is observed that the generalized creep correlation from the FeCrAl handbook is applied to APMT, C06M, and C36M and a specific model suggested by [34] is applied to C35M. The resulting failure at lower pressures (and correspondingly earlier times) for $\mathrm{C} 35 \mathrm{M}$ is due to a higher creep rate. Overall, under non-oxidizing conditions a slight improvement in time to failure may be observed at temperatures greater than $1100 \mathrm{~K}$ for the $\mathrm{FeCrAl}$ alloys analyzed.

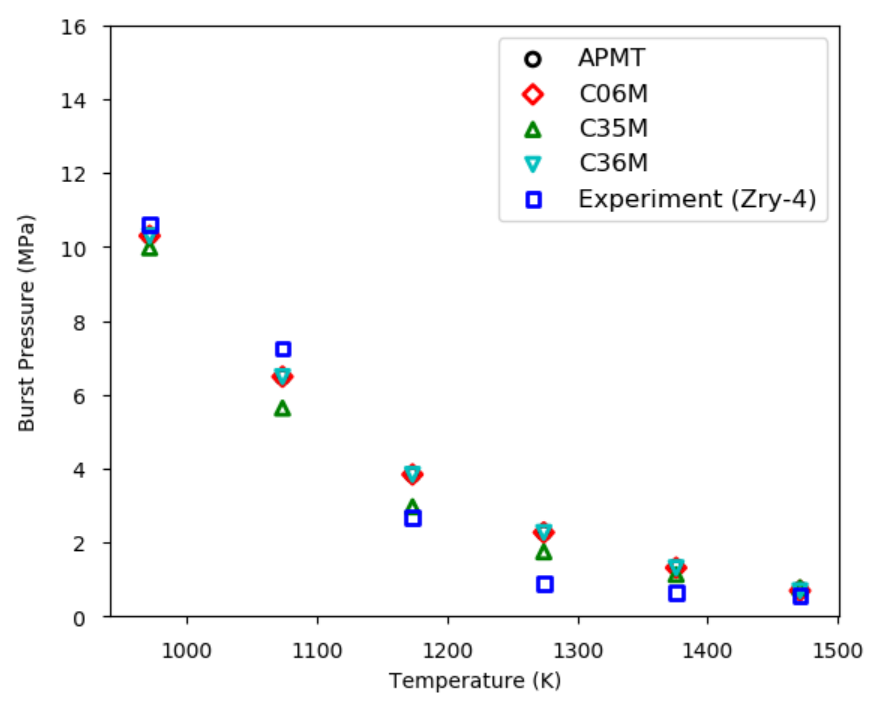

Figure 9: Comparison of the pressures at burst for the different FeCrAl alloys to the experimental measurements for Zircaloy-4 for the selected PUZRY cases.

\subsubsection{Tritium Permeability}

To demonstrate the tritium permeability model implemented in Bison for $\mathrm{FeCrAl}$ a simple case was considered based upon [41]. Here, a fuel pellet with an $8.2 \mathrm{~mm}$ diameter is subjected to a linear heat generation rate of $22000 \mathrm{~W} / \mathrm{m}$. Assuming $200 \mathrm{MeV}$ is released per fission, the fission rate can be calculated to be $1.26 \times 10^{19}$ fissions $/ \mathrm{m}^{3}$-s. The clad has a thickness of $385 \mu \mathrm{m}$ as required to overcome the neutronic penalty associated with FeCrAl. The concentration of tritium at the outer surface of the clad is fixed at zero. The simulation time is 50 hours (180 $000 \mathrm{~s}$ ). Figure 10 illustrates the tritium concentration profile through the clad at the end of the simulation. The results are similar to that of [41] except the permeability of APMT was chosen for this analysis. 


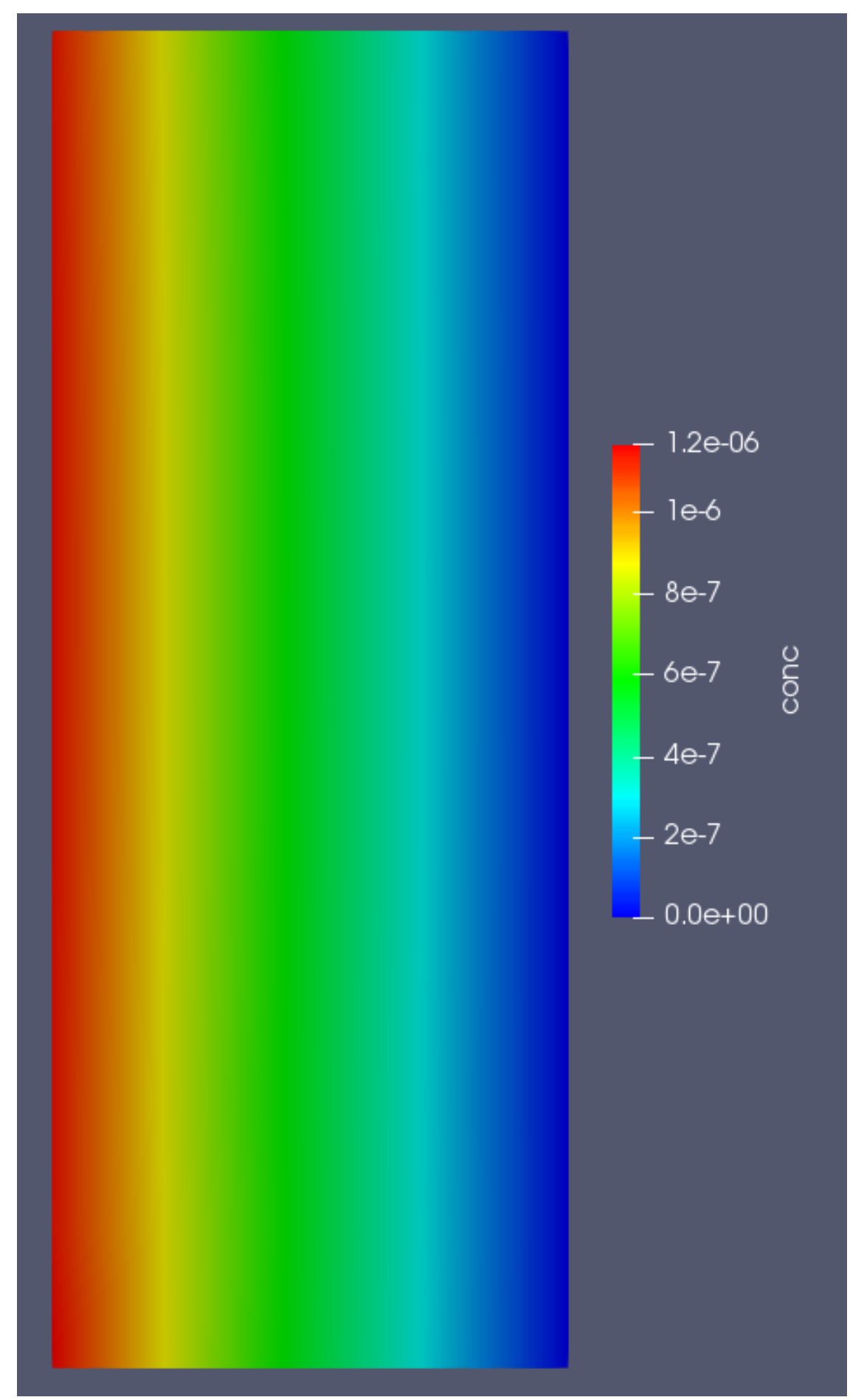

Figure 10: Tritium concentration profile at the end of the simulation. The concentration units are $\mathrm{mol} / \mathrm{m}^{3}$. 


\section{Uncertainty Quantification and Sensitivity Analysis}

Sensitivity analysis and uncertainty quantification provide detailed information about propagation of uncertainty on input models on the output metrics of interest as well as which inputs have the strongest correlation with the outputs. In the following subsections the uncertainty quantification is provided as a $\pm 2 \sigma$ about the mean. In the case sensitivity analysis the Pearson correlation coefficients, which identify linear relationships between inputs and outputs are presented. The uncertainty quantification and sensitivity analysis are performed by coupling Bison to the Dakota [43]. In all cases, Latin Hypercube Sampling (LHS) is used that reduces the required amount of samples for the analyses.

\subsection{Cr-Coated Clad Ballooning Behavior}

In Chapter 5 a parametric study was performed to compare the ballooning behavior between Cr-coated and uncoated clads using the nominal values calculated from the material models described in Chapters 2 and 3 . A single combination of parameters from parametric study was chosen to perform a more detailed sensitivity analysis on the input models. The parameters selected include a coating thickness of $20 \mu \mathrm{m}$, a maximum clad temperature of $1000 \mathrm{~K}$, a pressure ramping rate of $10 \mathrm{kPa} / \mathrm{s}$ and an initial fast fluence of $2.5 \times 10^{25} \mathrm{n} / \mathrm{m}^{2}$. The models selected for variation as part of the sensitivity analysis and uncertainty quantification are summarized in Table 19 including the model, its nominal value, the range on a scaling factor multiplying the nominal value (obtained from the uncertainties in the models), and the assumed distribution of the scaling factor. The output metric of the study is the time to failure for both uncoated and coated cases. For each substrate, 400 cases were run for the coated tube and 200 cases for the uncoated tube (only the last four inputs were varied in the uncoated case), resulting in a total of 1800 simulations.

Table 19: Parameters considered in the sensitivity analysis for Cr-coated zirconium-based clads and corresponding ranges of variation.

\begin{tabular}{llll}
\hline Parameter & Nominal Value & Scaling factor range & Distribution \\
\hline Chromium thermal conductivity & See Equation 31 & {$[0.95 ; 1.05]$} & Normal \\
Chromium thermal expansion coefficient & See Equation 33 & {$[0.9 ; 1.1]$} & Normal \\
Chromium Young's modulus & See Equation 34 & {$[0.9 ; 1.1]$} & Normal \\
Chromium Poisson's ratio & 0.22 & {$[0.85 ; 1.15]$} & Normal \\
Chromium creep rate & See Equation 35 & {$[0.8 ; 1.2]$} & Normal \\
Chromium yield stress & See Equation 36 & {$[0.8 ; 1.2]$} & Normal \\
Substrate thermal conductivity & See Equation 31 & {$[0.9798 ; 1.0202]$} & Normal \\
Substrate thermal expansion strain & See Equations 4 to 7 & {$[0.5 ; 1.5]$} & Normal \\
Substrate creep rate & See Equation 19 & {$[0.7 ; 1.3]$} & Normal \\
Substrate irradiation growth & See Equation 21 & {$[0.777 ; 1.223]($ Zry-4) } & Normal \\
& See Equation 21 & {$[0.814 ; 1.186]\left(\mathrm{MS}^{\circledR}\right)$} & Normal \\
& See Equation 21 & {$[0.552 ; 1.448]\left(\right.$ ZIRLO $\left.^{\mathrm{TM}}\right)$} & Normal \\
\hline
\end{tabular}

Table 20 shows the mean time to burst for the uncoated and coated tubes for each substrate including $\pm 2 \sigma$. As expected, the coated clad tubes burst at a later time indicating smaller balloons at any specific time. The results do not differ much between the substrates as previously observed. Until the oxidation kinetics of ZIRLO ${ }^{\mathrm{TM}}$ and $\mathrm{M} 5^{\circledR}$ is publicly available, one cannot expect much difference between the results. The minor differences between the alloys is attributed to the different uncertainties in irradiation growth and cold work of the different substrates.

Table 20: The mean time to burst with the associated $\pm 2 \sigma$ uncertainty for the various substrates.

\begin{tabular}{lccc}
\hline & Zircaloy-4 & M5 $^{\circledR}$ & ZIRLO $^{\text {TM }}$ \\
\hline Coated & $790.12 \pm 26.39$ & $790.35 \pm 26.40$ & $789.96 \pm 26.40$ \\
Uncoated & $678.29 \pm 26.65$ & $678.55 \pm 26.68$ & $678.29 \pm 26.65$ \\
\hline
\end{tabular}

The Pearson correlation coefficients for the Cr-coated studies are shown in Figure 11. For both the uncoated and coated case for all substrates a single input model had a strong linear relationship with the time to burst metric, the creep rate 
of the substrate. The relationship is negative indicating as the creep rate increases the time to failure decreases. This makes sense the critical inelastic strain will be attained at an earlier time if the tube creeps at a faster rate. Thermal conductivity of the models do not influence the outputs in this study because the temperature remains constant during the pressure loading. For the coated case, two other parameters have a small linear correlation with the time to burst, the yield stress and creep rate of the coating. Increasing the yield strength of the coating causes the overall tube to be stronger resulting in a slight increase in time to failure. As with the substrate, the creep rate of the coating is negatively correlated with the time of burst, but to a much lesser extent.

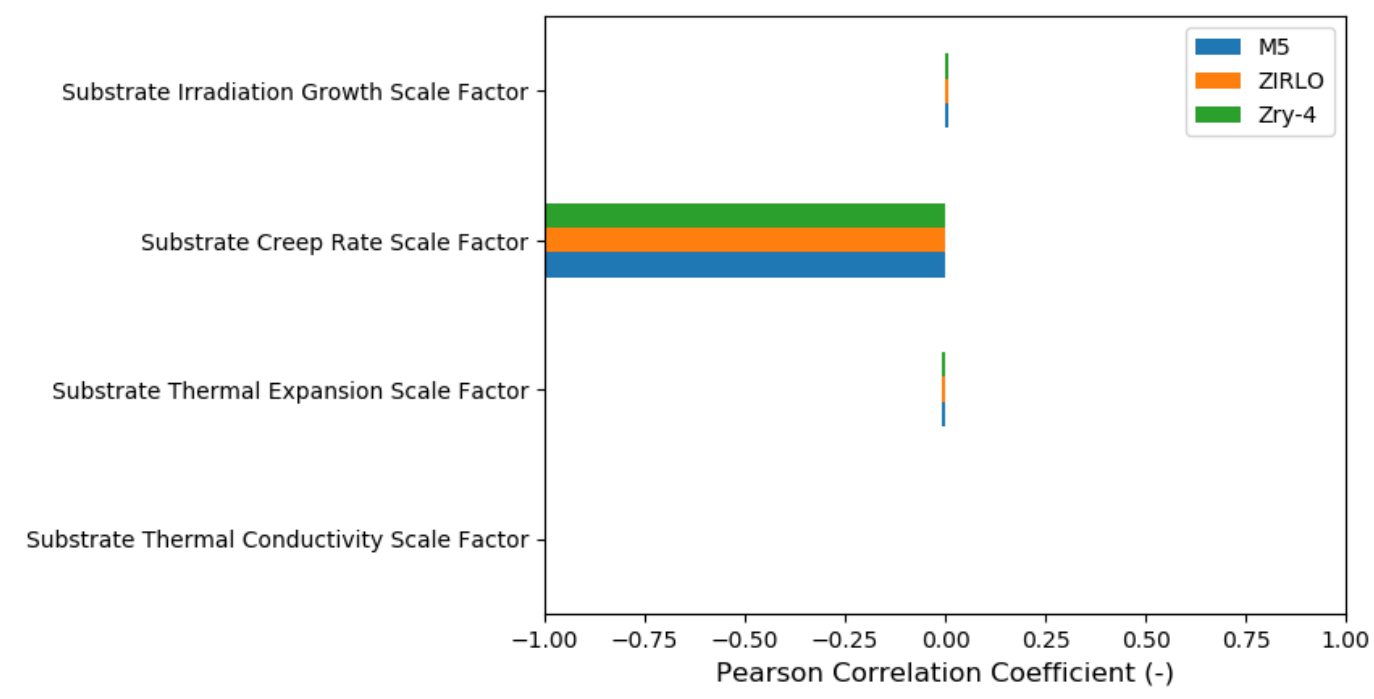

(a)

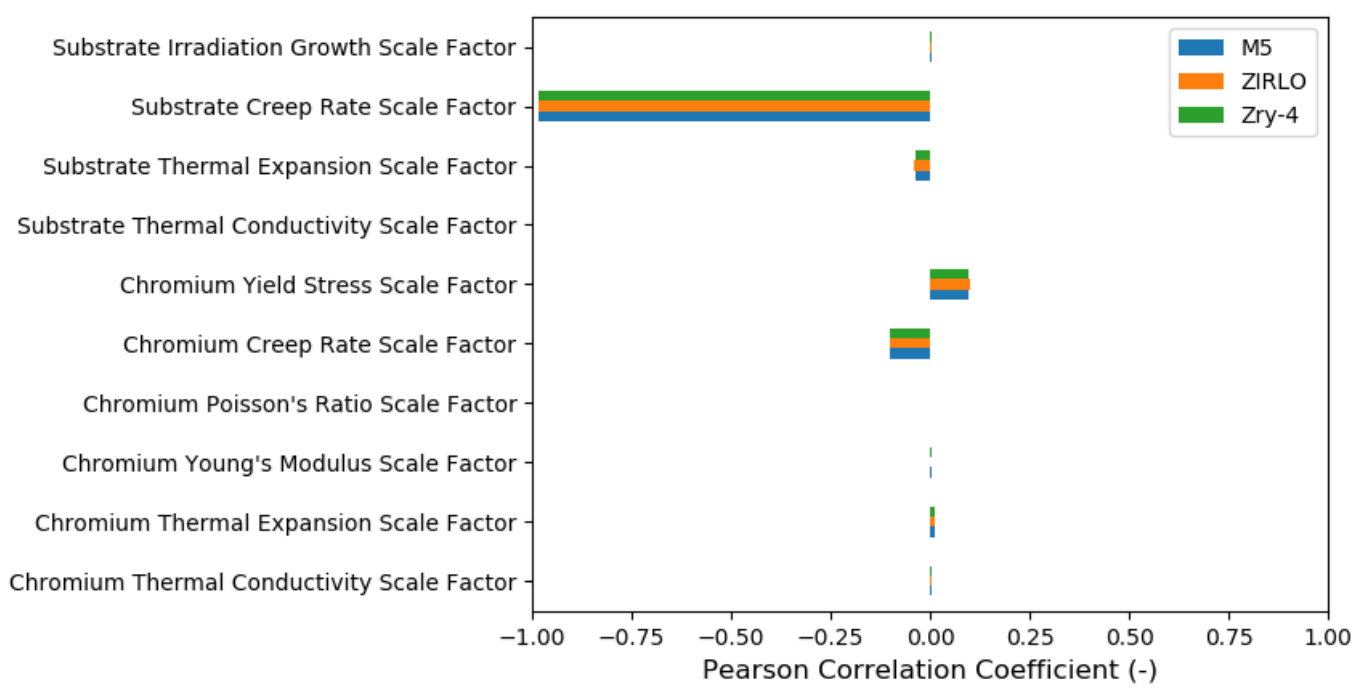

(b)

Figure 11: Pearson correlation coefficients for the (a) Cr-coated and (b) uncoated clad tubes between the sensitive inputs and the time to burst.

\subsection{FeCrAl Ballooning Behavior}

A select subset of the PUZRY non-oxidizing experiments were investigated on $\mathrm{FeCrAl}$ tubes in Chapter 5 using the nominal values computed from the material models described in 4 . Case 30 was selected for the sensitivity analysis 
and uncertainty quantification, which was at an isothermal temperature of $1073.55 \mathrm{~K}$ and had a pressurization rate of $0.0263 \mathrm{MPa} / \mathrm{s}$. Table 21 summarizes the selected parameters that are varied as part of the analysis including the nominal value, scale factor range that is multiplying the nominal equations (obtained from the uncertainty in the models), and the assumed distribution of the scaling factor. 400 cases were simulated for each FeCrAl alloy (APMT, C06M, C35M, C36M for a total of 1600 simulations.

Table 21: Parameters considered in the sensitivity analysis for the FeCrAl ballooning analysis and corresponding ranges of variation.

\begin{tabular}{llll}
\hline Parameter & Nominal Value & Scaling factor range & Distribution \\
\hline Thermal conductivity & See Equation 39 & {$[0.93 ; 1.07]$} & Normal \\
Thermal expansion coefficient & See Equation 42 & {$[0.92 ; 1.08]$} & Normal \\
Young's modulus & See Equation 43 or Table 16* & {$[0.94 ; 1.06]$} & Normal \\
Poisson's ratio & See Equation 44 or 0.3* & {$[0.8 ; 1.2]$} & Normal \\
Creep rate & See Equations 45 to 47* & {$[0.8 ; 1.2]$} & Normal \\
Yield stress & See Figure 5 & {$[0.75 ; 1.25]$} & Normal \\
Burst stress & See Equation 53 & {$[0.75 ; 1.25]$} & Normal \\
\hline *Depends
\end{tabular}

*Depends on alloy

Table 22 shows the mean pressure at burst for the various FeCrAl alloys including $\pm 2 \sigma$ alongside the experimental measurement from the Zircaloy-4 tube. For rod 30 using the nominal models in the previous chapter it was found that the $\mathrm{FeCrAl}$ tubes were found to fail at a lower pressure than the Zircaloy-4 experiment. By performing a statistical study it is found that the pressure at which the $\mathrm{FeCrAl}$ may burst can vary between over a wide range (4.5 - 7.5 MPa). As before, the C35M FeCrAl tubes bursts at a consistently lower pressure.

Table 22: The mean pressure at burst with the associated $\pm 2 \sigma$ uncertainty for various FeCrAl alloys.

\begin{tabular}{lc}
\hline Alloy & Pressure at Burst (MPa) \\
\hline APMT & $6.412 \pm 0.958$ \\
C06M & $6.412 \pm 0.958$ \\
C35M & $5.601 \pm 0.465$ \\
C36M & $6.412 \pm 0.958$ \\
Zircaloy-4 (Experiment) & 7.251 \\
\hline
\end{tabular}

The Pearson correlation coefficients for the FeCrAl study are shown in Figure 12. As expected the scaling factor on the burst stress is positively correlated to the pressure at burst. Increase the stress at which the tube fails requires a larger pressure to cause failure. The creep rate had a small negative correlation on the pressure at burst. At first, it may seem unintuitive as to why increasing the creep rate would decrease the pressure required to cause failure for a stress-based failure criterion. However, in Bison the analyses utilized a finite strain formulation which results in the increasing internal pressure boundary condition being applied to the deformed state of the tube. As the tube balloons, the localized inner radius increases resulting in a reduction of the clad thickness. A thinner tube requires a smaller load to reach a particular stress state. Hence, a larger creep rate results in a rapid increase in the balloon size causing more rapid failure. All of the other uncertain inputs had no correlation with the output due to the isothermal nature of the problem.

From the previous study, it could have been foreseen ahead of time that the burst stress scaling factor would have the strongest correlation. Therefore, the above study was repeated with the burst stress scaling factor fixed at 1.0 (the default behavior). Now, the uncertainty in the pressure at burst has decreased significantly from almost $1 \mathrm{MPa}$ to $\sim 0.1$ $\mathrm{MPa}$ indicating that for $\mathrm{FeCrAl}$ alloys the uncertainty in the burst stress is the most important. As before C35M bursts at a lower pressure than the other alloys.

Examining the Pearson correlation coefficients in Figure 13 for the study with the default burst stress behavior shows that the creep rate of the $\mathrm{FeCrAl}$ alloys now has a strong linear correlation. However, even though the correlation is linear the variation in the predicted results (See Table 23 is minimal indicating that the slope of the linear correlation is extremely small. 


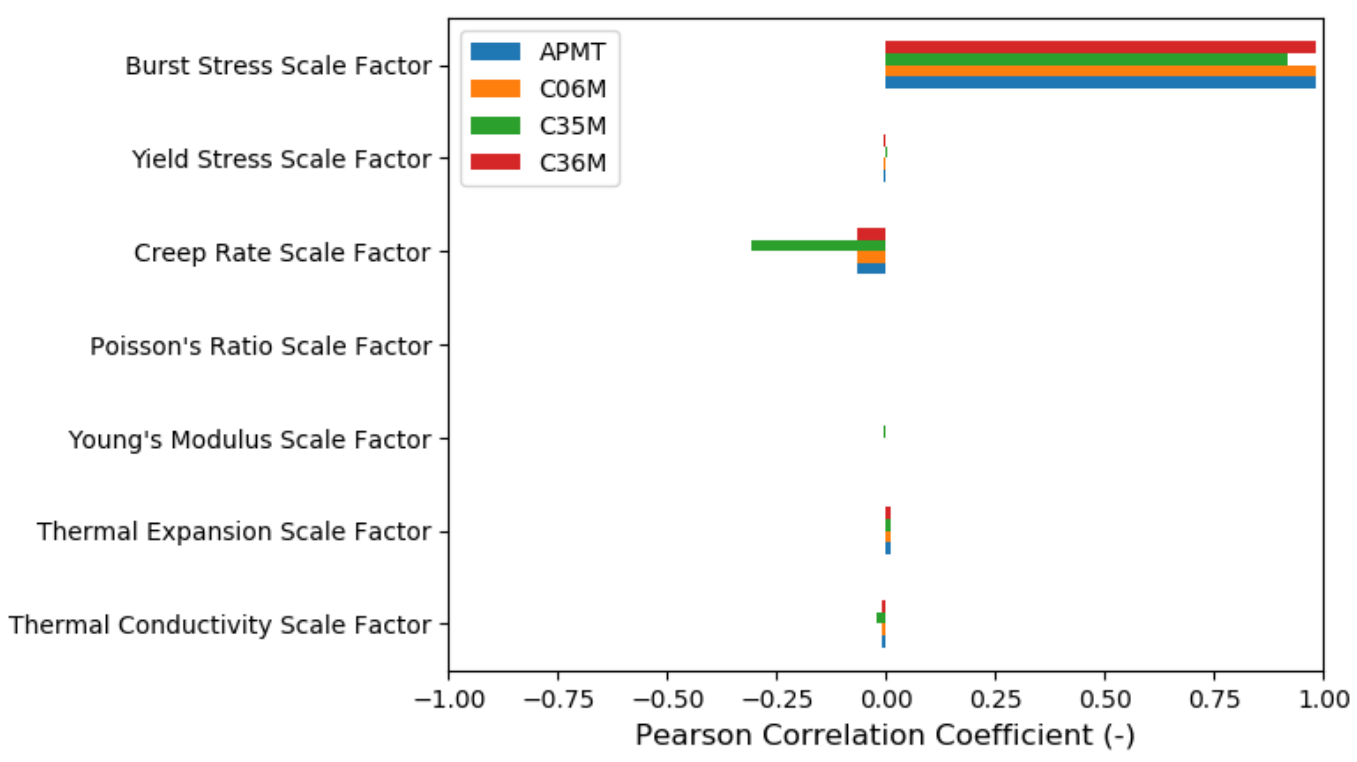

Figure 12: Pearson correlation coefficients between the sensitive inputs and the pressure at burst.

Table 23: The mean pressure at burst with the associated $\pm 2 \sigma$ uncertainty for various $\mathrm{FeCrAl}$ alloys when the burst stress is not scaled as part of the sensitivity study.

\begin{tabular}{lc}
\hline Alloy & Pressure at Burst (MPa) \\
\hline APMT & $6.492 \pm 0.071$ \\
C06M & $6.492 \pm 0.071$ \\
C35M & $5.646 \pm 0.153$ \\
C36M & $6.492 \pm 0.071$ \\
Zircaloy-4 (Experiment) & 7.251 \\
\hline
\end{tabular}

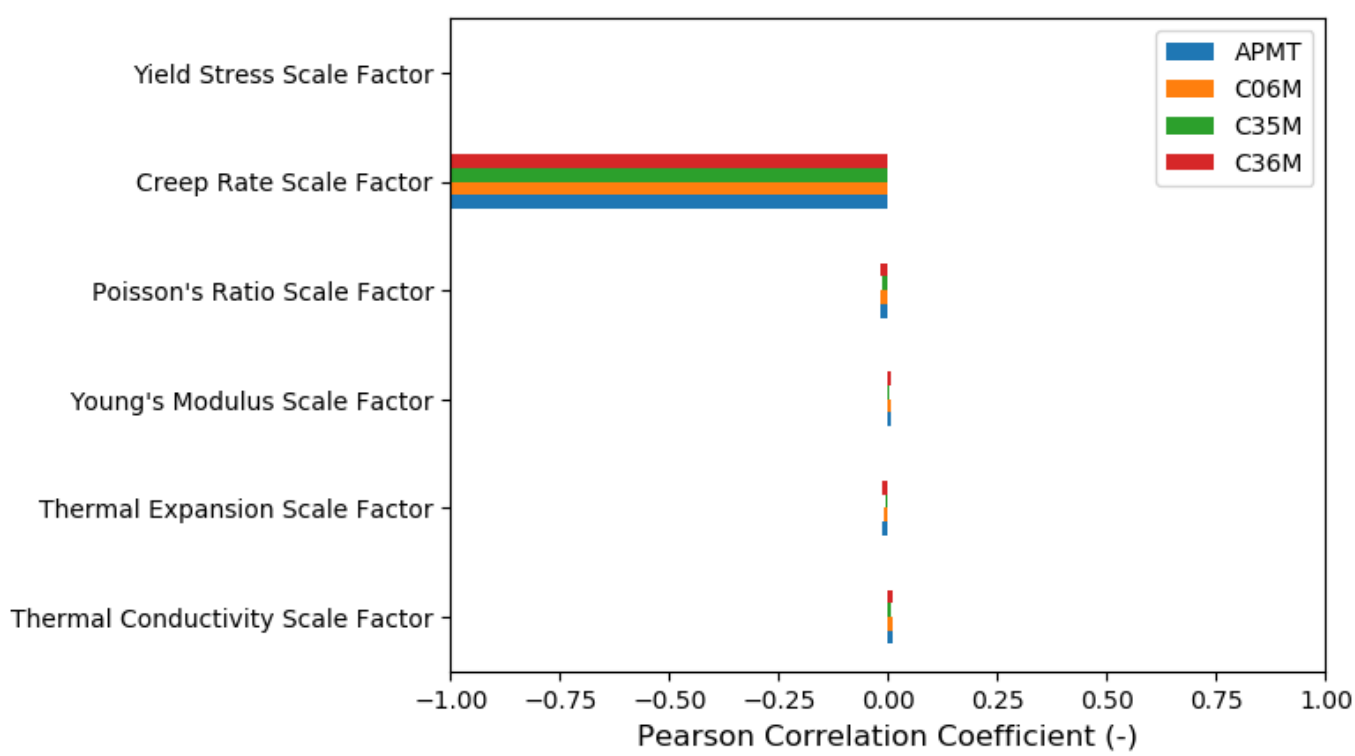

Figure 13: Pearson correlation coefficients between the sensitive inputs and the pressure at burst when the burst stress value is not scaled as part of the sensitivity study 


\section{Conclusions}

The primary focus of this report was listing the models available in Bison for the priority cladding concepts, Cr-coated zirconium-based clad and $\mathrm{FeCrAl}$ including the range of applicability of the model and an estimation of the uncertainty in model. Since all of the models for these materials were empirically derived the uncertainty was estimated from the experimental data upon which the model was created or based upon knowledge of similar materials.

Beyond providing a comprehensive overview of the models in a similar form to NUREG/CR-7024, the models were assessed in qualitative comparisons to conventional clads under the same operating conditions. The assessments were made in lieu of experimental data. Once data becomes available separate effects and integral validation needs to be completed. For Cr-coated clads a parametric study was performed to investigate and verify the claim that Cr-coated clads balloon less than uncoated clads under LOCA-like conditions. The results of the parametric study verified that assumption. For $\mathrm{FeCrAl}$, burst tests completed on Zircaloy-4 were revisited and $\mathrm{FeCrAl}$ behavior of four different alloys were compared against the Zircaloy-4 experimental results. It was observed that the predicted pressure for C35M was much lower than the other three alloys (APMT, C06M, C36M) primarily due to the differences in creep models. A study was also performed to verify the correct implementation of a model for tritium permeability in Bison. Finally, uncertainty quantification and sensitivity analysis were completed for the Cr-coated and $\mathrm{FeCrAl}$ burst studies by selecting one of the operational conditions. Select models were sampled within their estimated uncertainty and the effect on the Bison prediction of time to burst and pressure at burst was identified.

The work documented here significantly improves the documentation of the modeling capabilities currently available in Bison for fuel performance analyses of the NRC identified priority cladding concepts. 


\section{Acknowledgements}

This work was funded by the U.S. Department of Energy under the Consortium for Advanced Simulation of Light Water Reactors (CASL) program. This report has been authored by a contractor of the U.S. Government under Contract DE-AC07-05ID14517. Accordingly, the U.S. Government retains a non-exclusive, royalty free license to publish or reproduce the published form of this contribution, or allow others to do so, for U.S. Government purposes. 


\section{References}

[1] W. G. Luscher and K. J. Geelhood. Material property correlations: Comparisons between FRAPCON-3.5, FRAPTRAN-1.5 and MATPRO. Technical Report NUREG/CR-7024 Rev. 1, United States Nuclear Regulatory Commission, 2014.

[2] K. A. Gamble, T. Barani, D. Pizzocri, J. D. Hales, K. A. Terrani, and G. Pastore. An investigation of FeCrAl cladding behavior under normal operating and loss of coolant conditions. Journal of Nuclear Materials, 491:5566, 2017.

[3] Global Nuclear Fuel. GNF Delivers Accident Tolerant Fuel Assemblies for Plant Installation. https://www.genewsroom.com/press-releases/gnf-delivers-accident-tolerant-fuel-assemblies-plant-installation284233.

[4] Westinghouse Electric Company. Encore ${ }^{\mathrm{TM}}$ Fuel Brochure. http://www.westinghousenuclear.com/Portals/0/about/stories/2017/encore\%20fuel\%20brochure.pdf.

[5] Framatome. EATF, The Next Evolution in Nuclear Fuel. https://nextevolutionfuel.com/.

[6] R. L. Williamson, K. A. Gamble, D. M. Perez, S. R. Novascone, G. Pastore, R. J. Gardner, J. D. Hales, W. Liu, and A. Mai. Validating the BISON fuel performance code to integral LWR experiments. Nuclear Engineering and Design, 301:232 - 244, 2016.

[7] C. M. Allison, G. A. Berna, R. Chambers, E. W. Coryell, K. L. Davis, D. L. Hagrman, D. T. Hagrman, N. L. Hampton, J. K. Hohorst, R. E. Mason, M. L. McComas, K. A. McNeil, R. L. Miller, C. S. Olsen, G. A. Reymann, and L. J. Siefken. SCDAP/RELAP5/MOD3.1 code manual, volume IV: MATPRO-A library of materials properties for light-water-reactor accident analysis. Technical Report NUREG/CR-6150, EGG-2720, Idaho National Engineering Laboratory, 1993.

[8] International Atomic Energy Agency. Thermophysical properties database of materials for light water reactors and heavy water reactors: Final report of a coordinated research project 1999-2005. Technical Report IAEATECDOC-1496, IAEA, 2006.

[9] WJ Luscher and KJ Geelhood. Material property correlations: Comparisons between FRAPCON-3.5, FRAPTRAN-1.5, and MATPRO. Technical Report NUREG/CR-7024 Rev.1, Pacific Northwest National Laboratory, 2014.

[10] D. L. Hagrman and G. A. Reymann. MATPRO-Version 11: a handbook of materials properties for use in the analysis of light water reactor fuel rod behavior. Technical Report NUREG/CR-0497, TREE-1280, Idaho National Engineering Laboratory, 1979.

[11] F. J. Erbacher, H. J. Neitzel, H. Rosinger, H. Schmidt, and K. Wiehr. Burst criterion of Zircaloy fuel claddings in a loss-of-coolant accident. In Zirconium in the Nuclear Industry, Fifth Conference, ASTM STP 754, D.G. Franklin Ed., pages 271-283. American Society for Testing and Materials, 1982.

[12] M. Limbäck and T. Andersson. A model for analysis of the effect of final annealing on the in- and out-of-reactor creep behavior of zircaloy cladding. In Zirconium in the Nuclear Industry: Eleventh International Symposium, ASTM STP 1295, pages 448-468, 1996.

[13] DG Franklin. Zircaloy-4 cladding deformation during power reactor irradiation. In Zirconium in the Nuclear Industry. ASTM International, 1982.

[14] Y Rashid, R Dunham, and R Montgomery. Fuel Analysis and Licensing Code: FALCON MOD01. Technical report, Electric Power Research Institute, December 2004.

[15] I. G. Ritchie. Waterside corrosion of zirconium alloys in nuclear power plants. Technical Report IAEA TECDOC 996, IAEA, 1998. 
[16] F. Garzarolli, W. Jung, H. Shoenfeld, A. M. Garde, G. W. Parray, and P.G. Smerd. Review of PWR fuel rod waterside corrosion behavior. Technical Report EPRI NP-2789 Project 1250 Final Report, Kraftwerk Union A.G. and Combustion Engineering Inc., 1982.

[17] F. Garzarolli and M. Garzarolli. PWR Zr alloy cladding water side corrosion. Technical Report ANT International, ANT International, 2012.

[18] G. Schanz. Recommendations and supporting information on the choice of zirconium oxidation models in severe accident codes. Technical Report FZKA 6827, SAM-COLOSS-P043, Institut für Materialforschung, 2003.

[19] S. Leistikow, G. Schanz, H. v. Berg, and A.E. Aly. Comprehensive presentation of extended Zircaloy-4/steam oxidation results 600-1600 C. In CSNI/IAEA specialists meeting on water reactor fuel safety and fission product release in off-normal and accident conditions, Riso Nat. Lab., Denmark, 1983.

[20] J. V. Cathcart, R. E. Pawel, R. A. McKee, R. E. Druschel, G. J. Yurek, J. J. Campbell, and S. H. Jury. Zirconium metal-water oxidation kinetics, IV. reaction rate studies. Technical Report ORNL/NUREG-17, Oak Ridge National Laboratory, 1977.

[21] J. T. Prater and E. L. Courtright. Zircaloy-4 oxidation at 1300 to 2400 C. Technical Report NUREG/CR-4889, PNL-6166, Pacific Northwest Lab, 1987.

[22] T. Ikonen and V. Tulkki. The importance of input interactions in the uncertainty and sensitivity analysis of nuclear fuel behavior. Nuclear Engineering and Design, 275:229-241, 2014.

[23] V. Di Marcello, A. Schubert, J. van de Laar, and P. Van Uffelen. The TRANSURANUS mechanical model for large strain analysis. Nuclear Engineering and Design, 276:19-29, 2014.

[24] Malik Wagih, Benjamin Spencer, Jason Hales, and Koroush Shirvan. Fuel performance of chromium-coated zirconium alloy and silicon carbide accident tolerant fuel claddings. Annals of Nuclear Energy, 120:304 - 318, 2018.

[25] H. P. E. Armstrong. Dynamic young's modulus measurements above $1000^{\circ} \mathrm{C}$ on some some pure polycrystalline metals and commercial graphites. In Transactions of the Metallurgical Society, pages 962-966. American Institute of Mining, Metallurgical, and Petroleum Engineers, 1964.

[26] U. Holzwarth and H. Stamm. Mechanical and thermomechanical properties of commercially pure chromium and chromium alloys. Journal of Nuclear Materials, 300:161-177, 2002.

[27] C. W. Weaver. Irradiation and the ductility of chromium. Scripta Metallurgica, 2:463-466, 1968.

[28] M. Niffenegger and K. Reichlin. The proper use of thermal expansion coefficients in finite element calculations. Nuclear Engineering and Design, 243:356-359, 2012.

[29] J. Stephens and W. Klopp. High-temperature creep of polycrystalline chromium. Technical report, National Aeronautics and Space Administration, 1972.

[30] R. E. Stachowski, R. B. Rebak, W. P. Gassmann, and J. Williams. Progress of GE development of accident tolerant fuel FeCrAl cladding. In Proceedings of TopFuel, Boise, ID, USA, 2016.

[31] K. A. Terrani, S. J. Zinkle, and L. L. Snead. Advanced oxidation-resistant iron-based alloys for LWR fuel cladding. Journal of Nuclear Materials, 448:420-435, 2014.

[32] K. G. Field, M. A. Snead, Y. Yamamoto, and K. A. Terrani. Handbook on the material properties of fecral alloys for nuclear power production applications. Technical Report ORNL/SPR-2018/905 Rev. 1, Oak Ridge National Laboratory, 2018.

[33] Z. T. Thompson, K. A. Terrani, and Y. Yamamoto. Elastic Modulus Measurement of ORNL ATF FeCrAl Alloys. Technical Report ORNL/TM-2015/632, Oak Ridge National Laboratory, October 2015.

[34] K. A. Terrani, T. M. Karlsen, and Y. Yamamoto. Input correlations for irradiation creep of FeCrAl and SiC based on in-pile Halden test results. Technical Report ORNL/TM-2016/191, ORNL, May 2016. 
[35] S. R. J. Saunders, H. E. Evans, M. Li, D. D. Gohil, and S. Osgerby. Oxidation growth stresses in an aluminaforming ferritic steel measured by creep deflection. Oxidation of Metals, 48:189-200, 1997.

[36] K. G. Field, X. Hu, K. C. Littrell, Y. Yamamoto, and L. L. Snead. Radiation tolerance of neutron-irradiated model fe-cr-al alloys. Journal of Nuclear Materials, 465:746-755, 2015.

[37] Y. Yamamoto, B.A. Pint, K.A. Terrani, K.G. Field, Y. Yang, and L.L. Snead. Development and property evaluation of nuclear grade wrought $\mathrm{FeCrAl}$ fuel cladding for light water reactors. Journal of Nuclear Materials, 467:703716, 2015.

[38] Y. Yano, T. Tanno, Y. Sekio, H. Oka, S. Ohtsuka, T. Uwaba, and T. Kaito. Tensile properties and hardness of two types of 11cr-ferritic/martensitic steel after aging up to 45,000 h. Nuclear Materials and Energy, 000:1-7, 2016.

[39] K.A. Terrani, B.A. Pint, Y.-J. Kim, K.A. Unocic, Y. Yang, C.M. Silva, H.M. Meyer III, and R.B. Rebak. Uniform corrosion of fecral alloys in lwr coolant environments. Journal of Nuclear Materials, 479:36-47, 2016.

[40] Caleb P. Massey, Kurt A. Terrani, Sebastien N. Dryepondt, and Bruce A. Pint. Cladding burst behavior of Febased alloys under LOCA. Journal of Nuclear Materials, 470:128-138, 2016.

[41] Xunxiang Hu, Kurt A. Terrani, Brian D. Wirth, and Lance L. Snead. Hydrogen permeation in fecral alloys for LWR cladding application. Journal of Nuclear Materials, 461:282-291, 2015.

[42] C. San Marchi, B. P. Somerday, and S. L. Robinson. Permeability, solubility and diffusivity of hydrogen isotopes in stainless steels at high gas pressures. International Journal of Hydrogen Energy, 32(1):100-116, 2007.

[43] B. M. Adams, L. E. Bauman, W. J. Bohnhoff, K. R. Dalbey, M. S. Ebeida, J. P. Eddy, M. S. Eldred, P. D. Hough, K. T. Hu, J. D. Jakeman, J. A. Stephens, L. P. Swiler, D. M. Vigil, and T. M. Wildey. Dakota, a multilevel parallel object-oriented framework for design optimization, parameter estimation, uncertainty quantification, and sensitivity analysis: Version 6.0 user's manual. Technical Report SAND2014-4633 Version 6.3, Sandia National Laboratories, 2015.

[44] R. T. Sweet. Thermo-mechanical analysis of iron-chromium-aluminum (FeCrAl) alloy cladding for light water reactor fuel elements. $\mathrm{PhD}$ thesis, University of Tennessee, 2018.

[45] E. Perez-Feró, Z. Hózer, T. Novotny, G. Kracz, M. Horváth, I. Nagy, A. Vimi, A. Pintér-Csordás, Cs. Győri, L. Matus, L. Vasáros, P. Windberg, and L. Maróti. Technical Report FRL-2012-255-01/02, Center for Energy Research, Hungarian Academy of Sciences, 2013.

[46] J. Zhang and M. Veshchunov. Status update of the IAEA FUMAC project. Presented at the OECD/NEA Expert Group on Reactor Fuel Performance (EGRFP), Paris, France, February 16, 2016.

[47] K. Kulacsy. Communication within the IAEA Fuel Modelling under Accident Conditions (FUMAC) Project, 2015. 